\title{
Design of Highly Selective Pt Nanoparticle Catalysts for Aerobic Oxidation of KA-Oil using Continuous-Flow Chemistry
}

\author{
Arran M. Gill, ${ }^{[a]}$ Christopher S. Hinde, ${ }^{[a]}$ Rowan K. Leary, ${ }^{[b]}$ Matthew E. Potter,,${ }^{[a, c]}$ Andrea Jouve, ${ }^{[a, d]}$ \\ Peter P. Wells, ${ }^{[e, f]}$ Paul A. Midgley, ${ }^{[b]}$ John M. Thomas, ${ }^{[b]}$ and Robert Raja ${ }^{*[a]}$
}

\begin{abstract}
Highly active and selective aerobic oxidation of KA-oil, to cyclohexanone (precursor for adipic acid and $\varepsilon$-caprolactam) has been achieved in high yields using continuous-flow chemistry by utilizing uncapped noble metal nanoparticle ( $\mathrm{Au}, \mathrm{Pt} \& \mathrm{Pd})$ catalysts. These are prepared by a one-step in situ methodology, within threedimensional porous molecular architectures, to afford robust heterogeneous catalysts. Detailed spectroscopic characterization of the nature of the active sites at the molecular level, coupled with aberration-corrected scanning transmission electron microscopy, reveals that the synthetic methodology and associated activation procedures play a vital role in regulating the morphology, shape and size of the metal nanoparticles. These active centers have a profound influence on the activation of molecular oxygen for selective catalytic oxidations.
\end{abstract}

Cyclohexanone is an important commodity chemical used in the production of adipic acid and $\varepsilon$-caprolactam, which are essential precursors used in the industrial manufacture of nylon 6,6 and nylon 6 respectively. ${ }^{[1]}$ The selective hydrogenation of phenol, ${ }^{[2]}$ direct oxidation of cyclohexane ${ }^{[3]}$ and dehydrogenation of cyclohexanol[4] are commonly used for the production of cyclohexanone, either in its pure form or as KA-oil (a mixture of cyclohexanol and cyclohexanone). Given the challenges associated with the aerobic oxidation of hydrocarbons ${ }^{[5]}$ using heterogeneous catalysts, dehydrogenation of cyclohexanol or KA-oil has proved commercially attractive. ${ }^{[4]}$ In this Communication, we explore the prospects for the aerobic oxidation of KA-oil using heterogenized metal nanoparticle (NP) catalysts (Figure 1). In particular, we have focused on developing a continuous-flow system ${ }^{[6]}$ that would enhance the current yields obtained by the dehydrogenation route, whilst at the same time maximizing the overall selectivity $(>99 \%)$ to the desired cyclohexanone product.

Noble metal NPs, including $\mathrm{Pt}, \mathrm{Pd}$ and $\mathrm{Au}$, have demonstrated a precedent for exceptional activity in a number of selective oxidation and hydrogenation processes. ${ }^{[7]}$ Interestingly, the use of metal NPs in the oxidation of cyclohexanol (and KA-oil in particular) under continuous-flow conditions, is somewhat limited (see Table SI1a). Au/Cu-fiber NP catalysts ${ }^{[8]}$ produce

[a] A. M. Gill, Dr. C. S. Hinde, Dr. M. E. Potter, A. Jouve \& Dr. R. Raja University of Southampton, Southampton, SO17 1BJ, UK. E-mail: R.Raja@soton.ac.uk

[b] Dr. R. K. Leary, Prof. P.A. Midgley and Prof. Sir J. M. Thomas University of Cambridge, Cambridge, CB3 OFS, UK.

[c] Dr. M. E. Potter

Georgia Institute of Technology, Atlanta, 30332-0100, USA.

[d] A. Jouve

University of Turin, Via P. Giuria 7, 10125, Turin, Italy.

[e,f] Dr. P. P. Wells

UK Catalysis Hub, Oxford, OX11 OFA, UK.

University College London, London, WC1H OAJ, UK.

Supporting information for this article is given via a link at the end of the document.

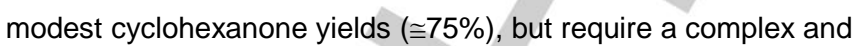
intensive catalyst synthesis procedure. A range of $\mathrm{Cu}$-based catalysts, ${ }^{[9]}$ and other transition-metal variants employing $\mathrm{Ti}$, Co and $\mathrm{Mn}^{[10]}$ active centers have been investigated, notwithstanding the fact that a large proportion of these catalysts require high concentrations of corrosive initiators, co-solvents and stoichiometric oxidants. Table SI1a highlights some relevant examples of cyclohexanol oxidation and dehydrogenation. It further demonstrates the limited use of continuous-flow methods, with a large majority of catalytic processes utilizing a batch set-up. Developing low-temperature, selective oxidation of KA-oil could therefore be potentially attractive if cyclohexanone selectivities and yields can rival traditional cyclohexanol oxidation and dehydrogenation pathways. ${ }^{[3,4]}$

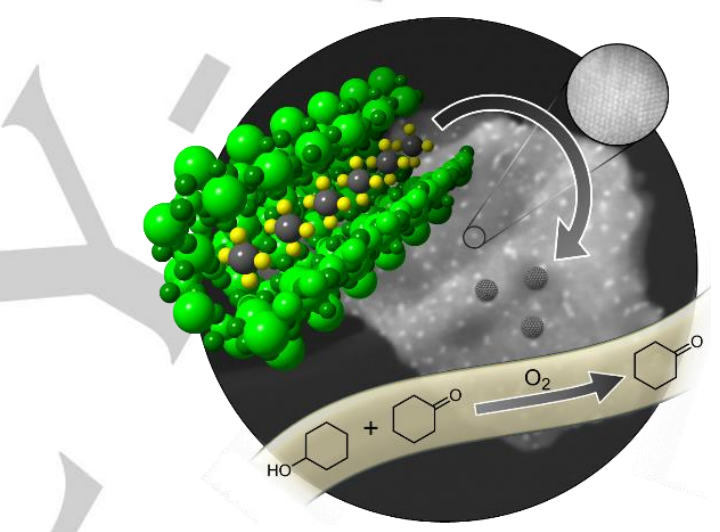

Figure 1. Graphical illustration of the microporous framework architecture containing precursor complexes, which result in well-dispersed and isolated metallic NPs upon activation (as visualized by AC-STEM), that are highly active and selective for the aerobic oxidation of KA-oil.

In this study we capitalize ${ }^{[11]}$ on exploiting the synergistic potential of microporous copper chlorophosphate (CuCIP) frameworks bearing flexible anion exchange properties, and devising new synthetic strategies for generating (see SI2) in situ, isolated and well-defined NPs of Pt, Pd and $\mathrm{Au}(2-5 \mathrm{~nm})$, as embodied in Figure 1. In particular, changes in the local structural environment of the NPs were monitored over a range of activation temperatures using $x$-ray absorption spectroscopy (XAS). The shape- and size-distribution of the active sites within the microporous support architecture were probed using aberrationcorrected scanning transmission electron microscopy (AC-STEM) and the compositional integrity of the NPs was ascertained using complementary energy-dispersive $\mathrm{x}$-ray spectroscopy (STEMEDXS). The findings from here have been rationalized with a view to evaluating structure-property relationships in catalytic studies involving the activation of molecular oxygen. The stability of these solid NPs and versatility of this approach has been investigated in the aerobic oxidation of KA-oil, under continuous-flow conditions thereby affording potential scope for the industrial applicability of these catalysts. ${ }^{[6]}$ 

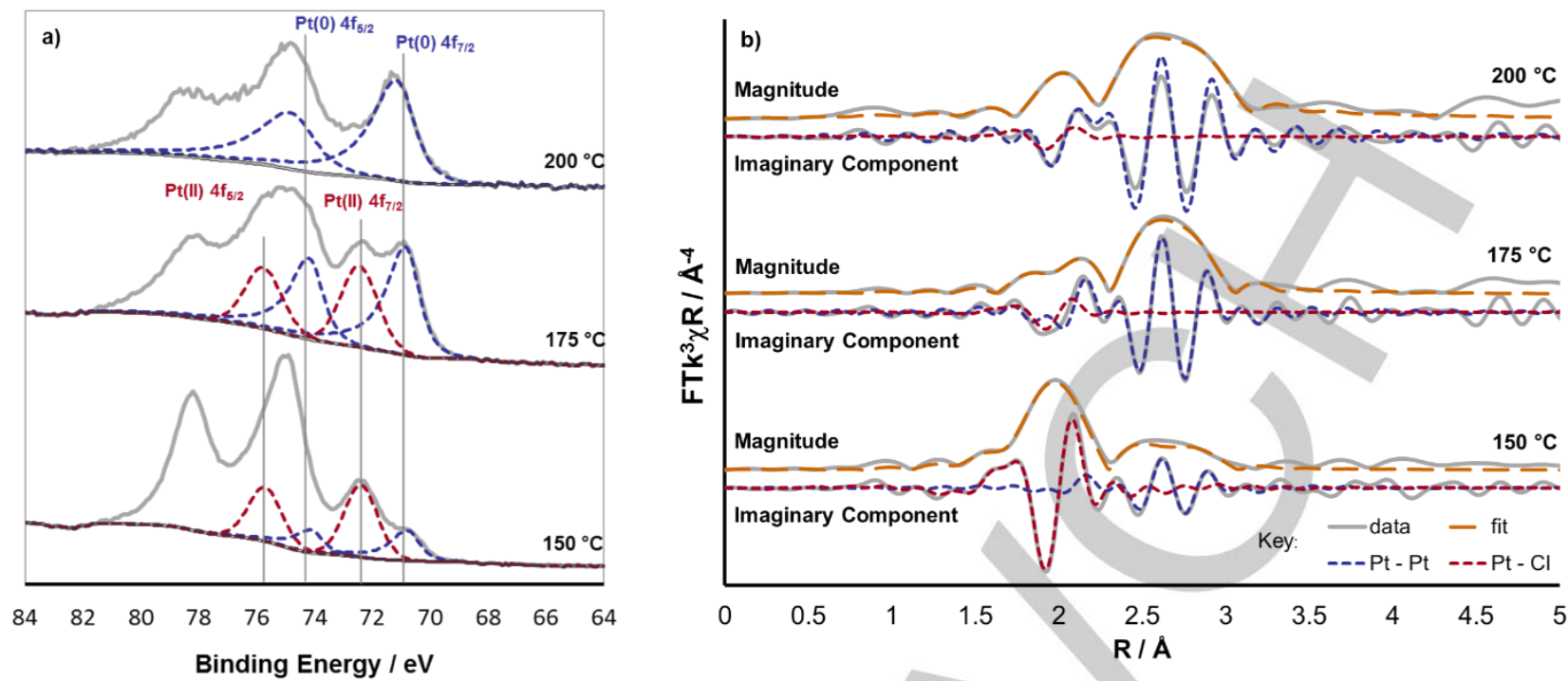

Figure 2. 2a depicts the XPS spectra and $2 \mathrm{~b}$ the magnitude and imaginary component of the $\mathrm{k}^{3}$ weighted Fourier transform for the EXAFS data of the three Pt/CuCIP species reduced under different activation temperatures. Both techniques demonstrate the progressive reduction of the $[\mathrm{PtCl} 4]^{2-}$ precursor towards the metallic $\mathrm{Pt}(0)$ species with increase in temperature. Figure $2 \mathrm{a}$ is plotted with reference samples in Figure $\mathrm{SI} 3 \mathrm{a}$. For Figure $2 \mathrm{~b}$ the associated scattering paths are included for the imaginary component and the fitting parameters are displayed in Table SI4a.

X-ray photoelectron spectroscopy (XPS) was employed to probe the nature of noble metal species adjacent to the surface of the microporous framework, with respect to different activation temperatures (Figure 2a and SI3). A clear trend was observed for the $\mathrm{Pt} / \mathrm{CuCIP}$ catalyst, which showed a transition from a mixture of $\mathrm{Pt}(\mathrm{II})$ and $\mathrm{Pt}(0)$ with $4 \mathrm{f}_{7 / 2}$ peaks at $72.4 \mathrm{eV}$ and $70.8 \mathrm{eV}$ respectively, to purely $\mathrm{Pt}(0)$ species, as the activation temperature was progressively increased from 150 to $200{ }^{\circ} \mathrm{C}$ : (Figure 2a). Furthermore, it was established that an activation temperature of $200{ }^{\circ} \mathrm{C}$ was sufficient for the complete reduction of the Pt precursors to form NPs under these activation conditions.

XAS was used to probe the coordination geometry and local structural environment of the active sites with a view to gaining a better understanding on NP formation and extrusion, with progressive increase in activation temperatures. Concurrent trends with the XPS are exhibited in both the EXAFS (extended $X$-ray absorption fine structure) (Figure 2b) and XANES (X-ray absorption near edge structure) (Figure SI4a) data of the $\mathrm{Pt} / \mathrm{CuCIP}$ material, with evident progressive reduction of the $\left[\mathrm{PtCl}_{4}\right]^{2-}$ precursor species across the bulk of the sample. Figure $2 \mathrm{~b}$ demonstrates the significant decrease in contribution from Pt$\mathrm{Cl}$ neighboring atoms with a concurrent increase in Pt-Pt neighbors as a function of activation temperature. Analogously, due to the direct relationship between the white-line intensity of the $\mathrm{L}_{3}$-edge and the number of unoccupied $\mathrm{Pt} 5 d$ states, the diminishing white-line energies displayed in Figure SI4a suggest that the Pt species are approaching the metallic state with progressive increase in activation temperature. In addition, Table $\mathrm{SI} 4 \mathrm{a}$ shows that Pt-Pt bond lengths remain consistent with that expected of Pt NPs above $2.4 \mathrm{~nm}(2.76 \AA)^{[12]}$ and that the coordination numbers of the first shell Pt-Pt scattering path are also lower at 9.6(4) than would be expected of bulk Pt metal at $12 .{ }^{[13]}$ This indicates that an overwhelming majority of the $\left[\mathrm{PtCl}_{4}\right]^{2-}$ precursor are reduced to their metallic state with increase in activation temperature, as evidenced by the drastic reduction in the average coordination numbers of adjacent $\mathrm{Pt}$ atoms around the central Pt species. These observations juxtaposed with those of the Au and Pd systems (SI4) highlight the ease of extrusion of $\left[\mathrm{PtCl}_{4}\right]^{2-}$ species from the micropores, while corresponding PXRD data (SI5) confirms the retention of the structural integrity of the surrounding framework architecture. In the case of $\mathrm{Pt}$, it is clear that the presence of discrete precursor anions within the pores is not detrimental to the overall stability of the microporous framework structure. This is in contrast to that of the $\mathrm{Pd} / \mathrm{CuCIP}$ catalyst (Figure SI5d) where, at temperatures above $200^{\circ} \mathrm{C}$, the structural integrity becomes susceptible to additional phase impurities and degradation of the framework. This could be indicative of stronger interactions between the discrete $\left[\mathrm{PdCl}_{4}\right]^{2-}$ anions and the internal pores of the framework, which is currently being investigated.

The Au XAS (SI4) emphasizes that the $\left[\mathrm{AuCl}_{4}\right]^{-}$precursor requires much higher activation temperatures, ${ }^{[11 b]}$ despite the XPS showing surface species with slightly reduced binding energies, characteristic of nanoparticulate $\mathrm{Au}$, being generated above $200{ }^{\circ} \mathrm{C}$ (Figure SI3b), consistent with earlier work. ${ }^{[14]}$ This suggests that although metallic Au species form on the surface of these materials at $200{ }^{\circ} \mathrm{C}$, higher temperatures and/or alternate activation conditions might be required to achieve comparable extrusions to the Pt catalyst (a detailed study on this is currently underway and only comparable activation conditions are presented here for the sake of consistency). It is well-known that $\left[\mathrm{AuCl}_{4}\right]^{-}$is a non-selective oxidation catalyst; ${ }^{[15]}$ and the low activities observed in our catalytic studies (Figure $3 a$ ) with the $\mathrm{Au}$ catalyst, further vindicates the hypothesis that the adsorbed oxygen species need to be implicated with metallic $A u(0)$ sites for enhanced reactivity. ${ }^{[16]}$

The catalytic results for the aerobic oxidation of KA-oil with the Pt, Pd and Au catalysts, activated at different temperatures, is 

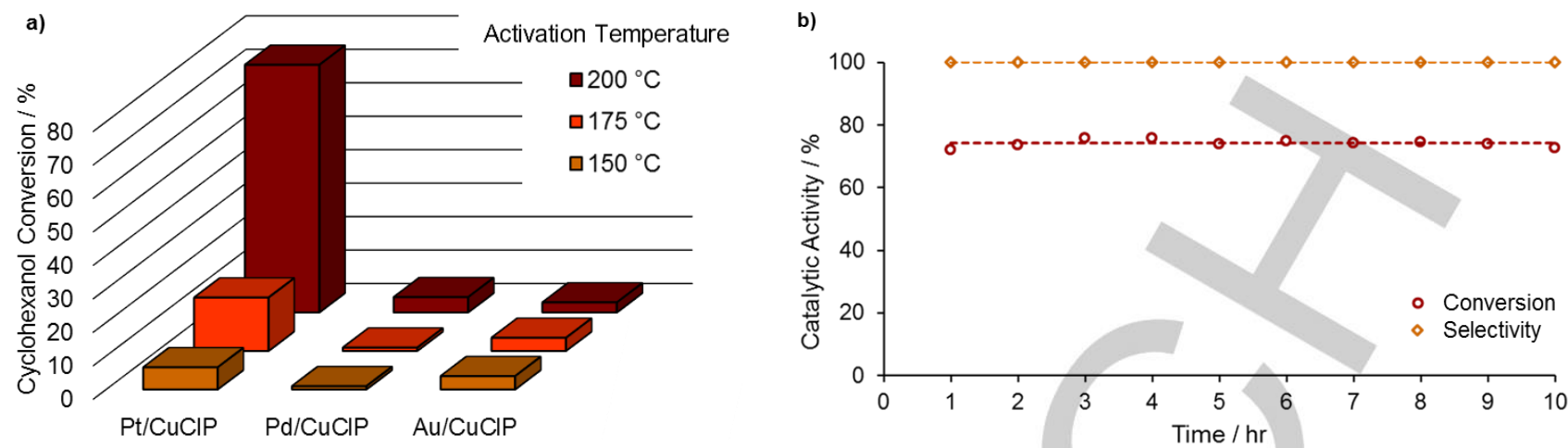

Figure 3. 3a contrasts the aerobic production of cyclohexanone with supported NP/CuCIP catalysts. Showing the superior activity of Pt/CuCIP for this process and the ability to optimize this reaction with adroit catalyst design. $3 \mathrm{~b}$ highlights the exceptional catalytic lifetime of the Pt/CuCIP catalyst, displaying consistent cyclohexanol conversion and cyclohexanone selectivity profiles over a $10 \mathrm{hr}$ period. Full tabulated data is presented in Tables SI7a and b respectively. Reaction temperature: $200{ }^{\circ} \mathrm{C}$, air flow: $25 \mathrm{mLmin}^{-1}$, substrate flow: $15 \mu \mathrm{Lmin}^{-1}$, WHSV: $1.8 \mathrm{hr}^{-1}$.

presented in Figure 3 (for further details see SI7). Figure 3a highlights the superior performance of the Pt catalyst over that of its corresponding Pd and $\mathrm{Au}$ analogues, and it is remarkable that the selectivity for the desired cyclohexanone was in excess of $99+\%$ for the Pt catalyst (reaction mixtures were analyzed for dibasic acids (including adipic acid) and we did not observe any evidence for their formation). Not only is the Pt/CuCIP a highly effective and selective aerobic oxidation catalyst (the undoped framework is inert, SI6), but the robust nature of this material is evidenced by both its ability to maintain high levels of activity and selectivity over extended periods on stream, as displayed in Figure $3 b$ (see also Figure SI7a). More importantly, the material retains its structural integrity post-catalysis as evidenced by both its sustained phase purity (Figures SI5b) and consistent NP size distribution (Figure SI8d), where no agglomeration or restructuring is observed, thus demonstrating the recyclability and stability (Table SI7d), of the catalyst. These findings support the hypothesis that the catalytic activity of these materials can be intrinsically linked to the degree of NP formation: the $\left[\mathrm{PtCl}_{4}\right]^{2-}$ precursor has a greater propensity for NP formation over a range of activation temperatures and this, in concert with the surrounding microporous architecture, bestows superior catalytic performance for the aerobic oxidation of KA-oil. In order to further understand this behavior, all three catalysts were examined using high-resolution STEM, in order to probe the shape- and sizedistribution of the NPs and, in particular, their precise location with respect to the crystalline structure of the microporous framework.

High-resolution studies, using AC-STEM, have shown in detail the abundant formation of nanocrystalline Pt NPs $(2-5 \mathrm{~nm}$ in diameter), which are well-dispersed on the CuCIP framework, whose crystalline integrity could also be visualized directly (Figures $4 \mathrm{a}, \mathrm{b}$ and SI8a). In this regard it is apparent that the atomic number contrast and often 'direct interpretability' of annular dark-field (ADF) STEM imaging, combined with the highspatial resolution enabled by AC optics, can yield significant insight into the crystallographic structures of both the extruded NPs and the microporous framework. Hence ADF AC-STEM can be a particularly powerful approach for the elucidation structureproperty relationships in these materials. The much more limited $\mathrm{NP}$ formation in the $\mathrm{Pd} / \mathrm{CuCIP}$ system is also readily apparent from AC-STEM, as exemplified in Figures 4c, $d$ and SI8b. Complementary compositional studies using STEM-EDXS also confirmed the well-defined nature of the Pt/CuCIP and Pd/CuCIP systems, with abundance and paucity of NPs, respectively (Figures SI9a and b).
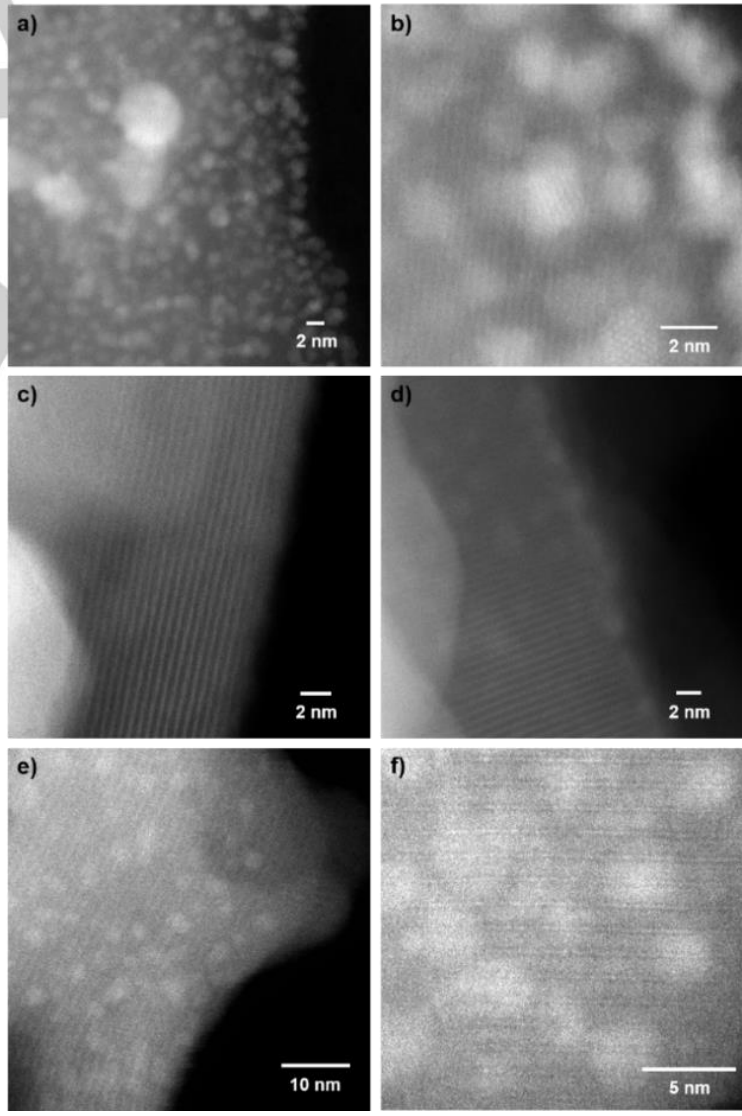

Figure 4. ADF AC-STEM images of the respective NP/CuCIP materials activated at $200{ }^{\circ} \mathrm{C}$. The crystalline structure of the framework is rendered visible via the lattice planes containing heavy atoms. $(a, b)$ showing abundance of Pt NPs; (c, d) limited Pd NP formation; $(e, f)$ prevalence of Au NPs within the CuCIP framework. Enlarged figures and further details are provided in SI8. 
The potentially more complex phenomena in the Au/CuCIP system (as seen from the EXAFS) was also systematically investigated in AC-STEM and STEM-EDXS studies, including samples activated at different temperatures. As shown in Figures $4 \mathrm{e}, \mathrm{f}, \mathrm{SI} \mathrm{c} \mathrm{c}$ and SI9c, regions of extensive well-defined small NP formation could be observed for the Au/CuCIP system, even when the sample was activated at $200^{\circ} \mathrm{C}$ (analogous to the Pt/CuCIP). Consistent with the XPS studies, these would appear to predominate at thin or surface regions of the framework. Further, STEM and spatially resolved STEM-EDXS elemental mapping on $\mathrm{Au} / \mathrm{CuCIP}$ samples activated at higher temperatures indicate an increased extrusion of both $\mathrm{Au}$ and $\mathrm{Cu}$, with some degree of intermixing. It therefore appears that the Au samples have the potential to possess a range of active species, including small extruded Au NPs on the surface as well as larger $\mathrm{Au}, \mathrm{Cu}$ or $\mathrm{Au}$ $\mathrm{Cu}$ NPs. These preliminary findings therefore indicate the potential for tailored $\mathrm{Au} / \mathrm{Cu}$ alloying or combined extrusion, which enhances the prospects for exploiting bifunctional (bimetallic) catalysis in the future ${ }^{[7 a-d]}$ (these aspects will be reported in detail in a future publication).

By employing a combination of complimentary structural, spectroscopic and high-resolution microscopy techniques, we have contrasted the varying degrees of NP formation and the superior properties of the $\left[\mathrm{PtCl}_{4}\right]^{2-}$ precursor to yield well-defined, isolated NPs (predominantly 2-3 nm) within microporous framework architectures. The local structural environment, and the precise nature and location of these active sites, is exigent for their superior performance (approaching unrivalled yields of $>90 \%$ by adapting a 'closed-loop' system, Table SI7d) in the aerobic oxidation of $\mathrm{KA}$-oil, under continuous-flow conditions. This design strategy further offers adequate scope for the creation of multimetallic (e.g. Au-Pt) and multifunctional heterogeneous catalysts, in our continued quest for the activation of molecular oxygen in sustainable catalytic processes. ${ }^{[17]}$

\section{Experimental Section}

Details on catalyst synthesis, activation, characterization and catalysis are provided in the Supporting Information. Briefly, the CuCIP framework doped with gold, platinum or palladium tetrachloride precursors were hydrothermally synthesized at $448 \mathrm{~K}$ for $48 \mathrm{hr} .{ }^{[11 \mathrm{a}]}$ Materials were postsynthetically activated under reduction for $2 \mathrm{hr}$ at specified temperatures $(423-523 \mathrm{~K})$ under a $150 \mathrm{mLmin}^{-1}$ flow of $5 \%$ hydrogen in nitrogen. The aerobic oxidation of KA-oil was studied under continuous-flow conditions under atmospheric pressure employing a custom-made fixed-bed reactor (Cambridge Reactor Design). A typical reaction setup consisted of $240 \mathrm{mg}$ of catalyst with a substrate flow rate of $15 \mu \mathrm{Lmin}^{-1}$ and an air flow rate of $25 \mathrm{mLmin}^{-1}$ at $473 \mathrm{~K}$. Products were analyzed and quantified by gas chromatography using appropriate calibrations using a $2 \mathrm{M}$ triethyleneglycol dimethyl ether in acetone external standard.

\section{Acknowledgements}

We thank Diamond Light Source (SP8071), the National EPSRC XPS User's Service (NEXUS), A*STAR (AMG \& CSH), Clare College Cambridge (RKL). EPSRC UK Catalysis Hub (EP/K014706/1, EP/K014668/1, EP/K014854/1 \& EP/K014714/1),
EU $7^{\text {th }}$ Framework Program (FP7/2007-2013, ESTEEM2, \#312483 (PAM), ERC \#291522-3DIMAGE (RKL \& PAM) are also thanked for financial assistance.

Keywords: Nanoparticle Catalysis • Aerobic Oxidation • FlowChemistry $\cdot$ KA-Oil Oxidation $\cdot$ High Selectivity

[1] a) W. B. Fisher, J. F. Van Peppen, Cyclohexanol and Cyclohexanone. Kirk-Othmer Encycl. Chem. Technol. John Wiley \& Sons, Inc. 2000, 17 ; b) M. T. Musser, Cyclohexanol and Cyclohexanone., Ullmann's Encycl. Ind. Chem. Wiley-VCH Verlag GmbH \& Co. KGaA, Weinheim. 2012, 4958; c) G. Franz, R. A. Sheldon, Oxidation., Ullmann's Encycl. Ind. Chem. Wiley-VCH Verlag GmbH \& Co. KGaA, Weinheim. 2012, 543-599.

[2] a) H. Liu, T. Jiang, B. Han, S. Liang, Y. Zhou, Science, 2009, 326, 1250 1252 ; b) J. Scharschmidt, C. Mendoza-Frohn, H. J. Buysch, R. Klotzbucher, Process for the Preparation of a Mixture of Cyclohexanone and Cyclohexanol., March 7, 1995, Patent No. US 5,395,976 A; c) J. F. Van Peppen, W. B. Fisher, Production of Cyclohexanone., May 30, 1978, Patent No. US 4,092,360.

[3] a) M. Dugal, G. Sankar, R. Raja, J. M. Thomas, Angew. Chem. Int. Ed. 2000, 39, 2310-2313; b) N. Tani, S. Murata, Method of Oxidizing Cyclohexane., February 8, 2003, Patent No. EP 1,350,783 B1.

[4] a) D. R. Cova, Preparation of Cyclohexanone., January 31, 1961, Patent No. US 2,970,172; b) C. F. Winans, Dehydrogenation of Alcohols., October 15, 1940, Patent No. US 2,218,457; c) A. Romero, A. Santos D. Escrig, E. Simon, Appl. Catal. A: General. 2011, 392, 19-27; d) R. Rao, S. K. Meher, B. G. Mishra, P. H. K. Charan, Catal. Today. 2012, 198, 140-147.

[5] a) G. W. Parshall, S. D. Ittel, Homogeneous Catalysis: The Applications and Chemistry of Catalysis by Soluble Transition Metal Complexes, $2^{\text {nd }}$ ed., Wiley-Interscience, New York, 1992; b) J. M. Thomas, R. Raja, G. Sankar, B. F. Johnson, D. W. Lewis, Chem. A Eur. J. 2001, 7, 29732978 ; c) C. L. Hill, Activation and Functionalization of Alkanes., WileyChichester, 1989, Chapters 6-8.

[6] R. Raja, A. B. Levy, S. Keenan, Nanoparticle Catalysts for the Conversion of Cyclohexanol to Cyclohexanone., October 30, 2015, US Patent (filed).

[7] a) L. Kesavan, R. Tiruvalam, M. H. A. Rahim, M. I. bin Saiman, D. I. Enache, R. L. Jenkins, N. Dimitratos, J. A. Lopez-Sanchez, S. H. Taylor, D. W. Knight, C. J. Kiely, G. J. Hutchings. Science. 2011, 331, 195-199; b) D. I. Enache, J. K. Edwards, P. Landon, B. Solsona-Espriu, A. F. Carley, A. A. Herzing, M. Watanabe, C. J. Kiely, D. W. Knight, G. J. Hutchings. Science. 2006, 311, 362-365; c) A. B. Hungria, R. Raja, R D. Adams, B. Captain, J. M. Thomas, P. A. Midgley, V. Golovko, B. F. G. Johnson, Angew. Chem. Int. Ed. 2006, 45, 4782-4785; d) S. Hermans, R. Raja, J. M. Thomas, B. F. G. Johnson, G. Sankar, D. Gleeson, Angew. Chem. Int. Ed. 2001, 40, 1211-1215; e) K. Mori, T. Hara, T. Mizugaki, K. Ebitani, K. Kaneda, J. Am. Chem. Soc. 2004, 126, 10657-10666; f) A. L. Tarasov, L. M. Kustov, A. A. Bogolyubov, A. S. Kiselyov, V. V Semenov, Appl. Catal. A Gen. 2009, 366, 227-231.

[8] G. Zhao, H. Hu, M. Deng, M. Ling, Y. Lu, Green Chem. 2011, 13, 55-58.

[9] a) G. R. Rao, S. K. Meher, B. G. Mishra, P. H. K. Charan, Catal. Today. 2012, 198, 140-147; b) B. M. Nagaraja, A. H. Padmasri, P. Seetharamulu, K. H. P. Reddy, B. D. Raju, K. S. R. Rao, J. Mol. Catal. A Chem. 2007, 278, 29-37; c) A. Romero, A. Santos, D. Escrig, E. Simón, Appl. Catal. A Gen. 2011, 392, 19-27.

[10] a) A. Corma, P. Esteve, A. Martnez, J. Catal. 1996, 161, 11-19; b) S. A. Chavan, D. Srinivas, P. Ratnasamy, J. Catal. 2002, 212, 39-45.

[11] a) C. S. Hinde, S. Van Aswegen, G. Collins, J. D. Holmes, T. S. A. Hor, R. Raja, Dalt. Trans. 2013, 42, 12600-12605; b) C. S. Hinde, D. Ansovini, P. P. Wells, G. Collins, S. Van Aswegen, J. D. Holmes, T. S. A. Hor, R. Raja, ACS Catal. 2015, 5, 3807-3816.

[12] J. H. Kang, L. D. Menard, R. G. Nuzzo, A. I. Frenkel, J. Am. Chem. Soc. 2006, 128, 12068-12069. 
[13] A. I. Frenkel, C. W. Hills, R. G. Nuzzo, J. Phys. Chem. B. 2001, 105, 12689-12703.

[14] a) J. T. Miller, A. J. Kropf, Y. Zha, J. R. Regalbuto, L. Delannoy, C. Louis, E. Bus, J. A. van Bokhoven, J. Catal. 2006, 240, 222-234; b) M. Turner V. B. Golovko, O. P. H. Vaughan, P. Abdulkin, A. Berenguer-Murcia, M. S. Tikhov, B. F. G. Johnson, R. M. Lambert, Nature. 2008, 454, 981-983.

[15] a) B. Pal, P. K. Sen, K. K. S. Gupta, J. Phys. Org. Chem. 2001, 14, 284 294; b) V. Soni, R. S. Sindal, R. N. Mehrotra, Polyhedron. 2005, 24, 1167-1174.

[16] a) B. Xu, X. Liu, J. Haubrich, R. J. Madix, C. M. Friend, Angew. Chem. Int. Ed. 2009, 48, 4206-4209; b) B. Xu, L. Zhou, R. J. Madix, C. M. Friend, Angew. Chem. Int. Ed. 2010, 49, 394-398.

[17] M. E. Potter, A. J. Paterson, B. Mishra, S. D. Kelly, S. R. Bare, F. Corà, A. B. Levy, R. Raja, J. Am. Chem. Soc. 2015, 137, 8534-8540. 


\section{COMMUNICATION}

Pt, Pd \& Au nanoparticles were generated in situ by anion extrusion from porous framework architectures. Spectroscopic and aberrationcorrected scanning transmission electron microscopy reveal that activation conditions are crucial for the generation of isolated active centers. The design strategy affords highly active and selective catalysts, for the industrially-significant aerobic oxidation of KA-oil, under continuousflow conditions.

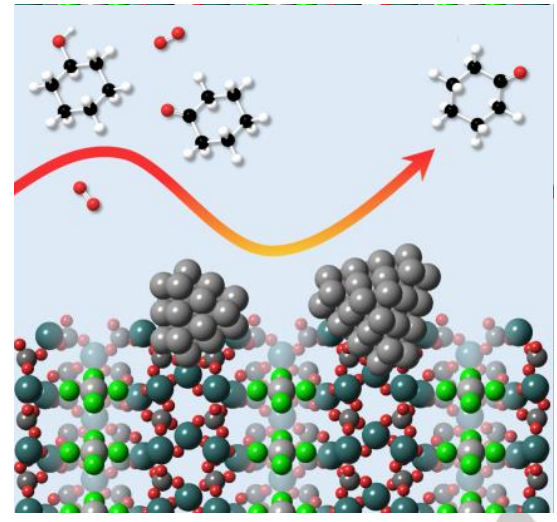

Arran M. Gill, Christopher S. Hinde, Rowan K. Leary, Matthew E. Potter, Andrea Jouve, Peter P. Wells, Paul A Midgley, John M. Thomas and Robert Raja*

Page No. - Page No.

Design of Highly Selective Pt Nanoparticle Catalysts for Aerobic Oxidation of KA-Oil using Continuous-Flow Chemistry 


\section{Supporting Information}

\section{Contents}

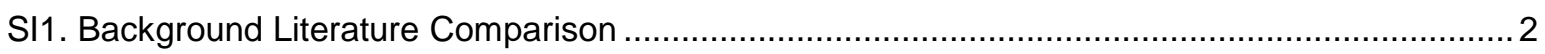

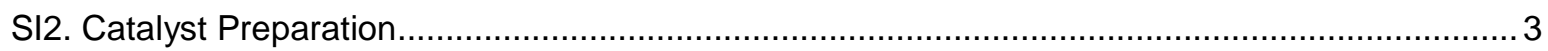

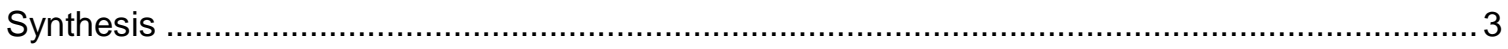

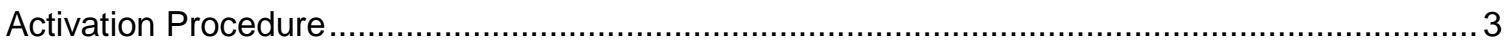

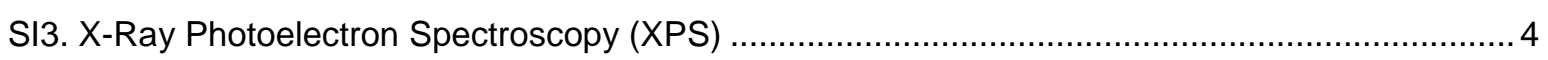

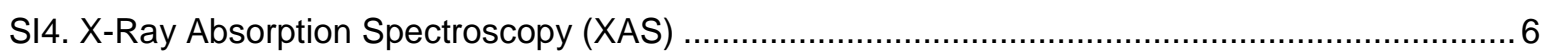

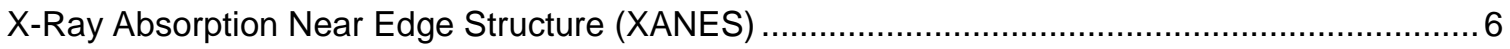

Extended X-Ray Absorption Fine Structure (EXAFS) …........................................................

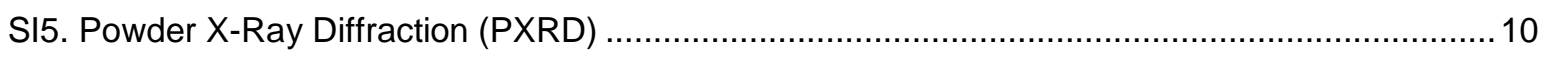

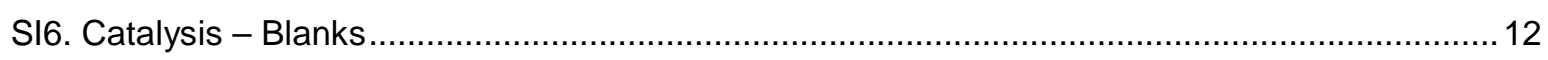

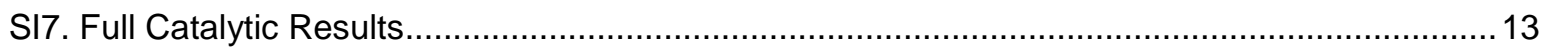

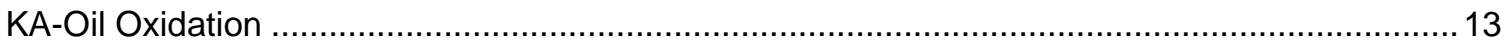

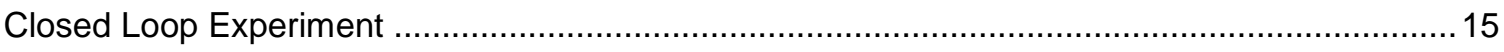

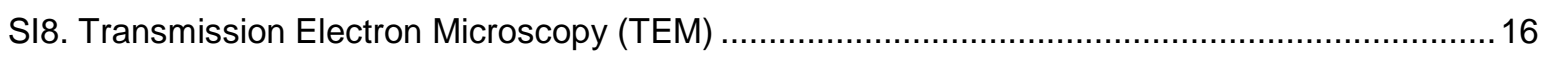

SI9. Energy-Dispersive X-Ray Spectroscopy (EDXS) …...................................................... 19

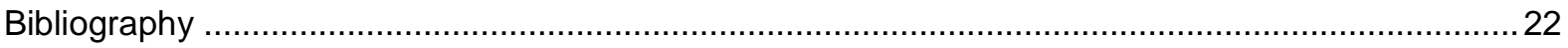


SI1. Background Literature Comparison

Table SIIa. Oxidation and dehydrogenation of cyclohexanol (or KA-oil) to cyclohexanone.

\begin{tabular}{|c|c|c|c|c|c|c|c|c|c|}
\hline $\begin{array}{c}\text { Ca } \\
\text { Active Species }\end{array}$ & $\begin{array}{l}\text { talyst } \\
\text { Support }\end{array}$ & Process & Substrate & Oxidant & $\begin{array}{l}\text { Temp. } \\
I^{\circ} \mathrm{C}\end{array}$ & $\begin{array}{c}\text { Time I } \\
\text { hr }\end{array}$ & $\begin{array}{c}\text { Cyol } \\
\text { Conv. I \% }\end{array}$ & $\begin{array}{c}\text { Cyone } \\
\text { Yield / \% }\end{array}$ & Ref. \\
\hline $\mathrm{RuO}_{2}$ & FAU & Batch & $\overline{\text { Cyol }}$ & Air & 80 & $\overline{4}$ & 43 & 43 & 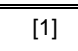 \\
\hline $\mathrm{Pt}$ & C & Batch & Cyol & Air & 150 & 5 & 100 & 0 & [2] \\
\hline $\mathrm{Pt}$ & Mg-ZSM-5 & Batch & Cyol & Air & 25 & 20 & 21 & 18 & [3] \\
\hline $\mathrm{CoMn}_{2}$ & Cluster Complexes & Batch & Cyol 50:50 Cyone & Air / HOAc & 90 & 4 & 91 & 0 & [4] \\
\hline $\mathrm{Ti}$ & Ti-Beta & Batch & Cyol & $\mathrm{H}_{2} \mathrm{O}_{2}$ & 65 & 3 & 44 & 24 & [5] \\
\hline $\mathrm{Ti}$ & Ti-Beta & Batch & Cyol & $\mathrm{H}_{2} \mathrm{O}_{2}$ & 65 & 5 & 10 & 10 & [6] \\
\hline $\mathrm{Au}$ & $\mathrm{TiO}_{2}$ & Batch & Cyol & $\mathrm{H}_{2} \mathrm{O}_{2}$ & 90 & 1 & 87 & 87 & [7] \\
\hline $\mathrm{Ti}$ & TS-1 & Batch & Cyol & $\mathrm{H}_{2} \mathrm{O}_{2}$ & 60 & 3 & 67 & 45 & [8] \\
\hline $\mathrm{Ru}$ & Silicotungstate & Batch & Cyol & $\mathrm{O}_{2}$ & 100 & 48 & 83 & 67 & [9] \\
\hline $\mathrm{Pt}$ & Solution & Batch & Cyol & $\mathrm{O}_{2}$ & 80 & 24 & 88 & 78 & [10] \\
\hline $\mathrm{Pt}$ & $\mathrm{BaO}$ & Batch & Cyol & $\mathrm{O}_{2}$ & 130 & 35 & 51 & 50 & [11] \\
\hline $\mathrm{Ru}$ & $\mathrm{Co}(\mathrm{OH})_{2} / \mathrm{CeO}_{2}$ & Batch & Cyol & $\mathrm{O}_{2}$ & 60 & 8 & 83 & 81 & [12] \\
\hline $\mathrm{Pd}$ & $\mathrm{CeO}_{2}$ & Batch & Cyol & $\mathrm{O}_{2}$ & 120 & 12 & 58 & 57 & [13] \\
\hline $\mathrm{V}_{2} \mathrm{O}_{3}$ & $\mathrm{KMn}_{8} \mathrm{O}_{16} \cdot \mathrm{nH}_{2} \mathrm{O}$ & Batch & Cyol & TBHP & 90 & 8 & 49 & 49 & [14] \\
\hline $\mathrm{Ag}$ & - & Flow & Cyol & Air & 580 & - & 10 & 10 & [15] \\
\hline $\mathrm{CuO} / \mathrm{CuCr}_{2} \mathrm{O}_{4}$ & $\mathrm{Al}_{2} \mathrm{O}_{3} / \mathrm{BaCr}_{2} \mathrm{O}_{4}$ & Flow & Cyol 95:5 Cyone & * & 290 & - & 80 & 66 & [16] \\
\hline $\mathrm{Pt} / \mathrm{Co}$ & $\mathrm{Al}_{2} \mathrm{O}_{3}$ & Flow & Cyol & * & 250 & - & 62 & 57 & [17] \\
\hline $\mathrm{Cu} / \mathrm{Ni}$ & $\mathrm{CeO}_{2}$ & Flow & Cyol & * & 350 & 1 & 42 & 38 & [18] \\
\hline $\mathrm{Fe} / \mathrm{Ti}$ & MCM-41 & Flow & Cyol & * & 240 & - & 86 & 54 & [19] \\
\hline $\mathrm{Cu}$ & $\mathrm{MgO} / \mathrm{Cr}_{2} \mathrm{O}_{3}$ & Flow & Cyol & * & 200 & - & 38 & 38 & [20] \\
\hline $\mathrm{Mn}$ & MCM-41 & Flow & Cyol & $\mathrm{O}_{2}$ & 250 & 5 & 52 & 40 & [21] \\
\hline
\end{tabular}

Cyol = Cyclohexanol, Cyone $=$ Cyclohexanone, TBHP $=$ tert-Butyl Hydroperoxide $.{ }^{*}=$ Dehydrogenation. 


\section{SI2. Catalyst Preparation}

\section{Synthesis}

Chemicals for synthesis were purchased from Sigma Aldrich or Fisher Scientific and used without further purification.

Materials were synthesized by adapting earlier protocols: ${ }^{[22]}$ Copper(II) fluoride $(0.1168 \mathrm{~g}, 1.150 \mathrm{mmol})$, $85 \mathrm{wt}$ \% orthophosphoric acid ( $0.2 \mathrm{~mL}, 2.922 \mathrm{mmol}), 50 \mathrm{wt} . \% \mathrm{RbOH}(0.24 \mathrm{~mL}, 2.037 \mathrm{mmol}), \mathrm{RbCl}(0.28$ $\mathrm{g} ; 2.316 \mathrm{mmol})$ and a source of $\mathrm{MCl}_{x} ; \mathrm{HAuCl}_{4}\left(0.0489 \mathrm{~g}, 0.144 \mathrm{mmol}, 7 \mathrm{wt}\right.$. \% Au), $\mathrm{K}_{2} \mathrm{PtCl}_{4}(0.0598 \mathrm{~g}$, $0.144 \mathrm{mmol}, 7 \mathrm{wt}$. \% Pt) or $\mathrm{K}_{2} \mathrm{PdCl}_{4}(0.0470 \mathrm{~g}, 0.144 \mathrm{mmol}, 4 \mathrm{wt}$. \% Pd) were mixed in the Teflon® liner of a custom-made $23 \mathrm{~mL}$ hydrothermal vessel. The vessel was sealed and heated to $448 \mathrm{~K}$ for 2 days.

Products formed as brilliant green cuboid crystals for both the Au and Pt material, and as light brown crystals for the Pd material. ${ }^{[22,23]}$

\section{Activation Procedure}

Gases were sourced from BOC Industrial Gases and used as purchased.

Materials were activated by reduction under a flow of $5 \% \mathrm{H}_{2} / \mathrm{N}_{2}$ at approx. $150 \mathrm{mLmin}^{-1}$, for 2 hours at the specified temperature, generating the active nanoparticle catalysts. After reduction, the Au material appeared unchanged in color, while the Pd material appeared black in color and the Pt catalyst a darker khaki-green. 


\section{SI3. X-Ray Photoelectron Spectroscopy (XPS)}

XPS analysis was performed using a Thermo Scientific K-Alpha instrument equipped with monochromated Al Ka source at the EPSRC XPS User's Service (NEXUS), University of Newcastle. A flood gun was used for charge compensation. A pass energy of $200 \mathrm{eV}$ and a step size of $1.0 \mathrm{eV}$ was employed for all survey spectra while a pass energy of $40 \mathrm{eV}$ and a step size of $0.1 \mathrm{eV}$ was used for high-resolution spectra of the elements of interest. All XPS spectra were calibrated against the carbon and/or oxygen 1s peaks, and high resolution spectra were fitted with Shirley backgrounds before peak analysis using the CasaXPS software.

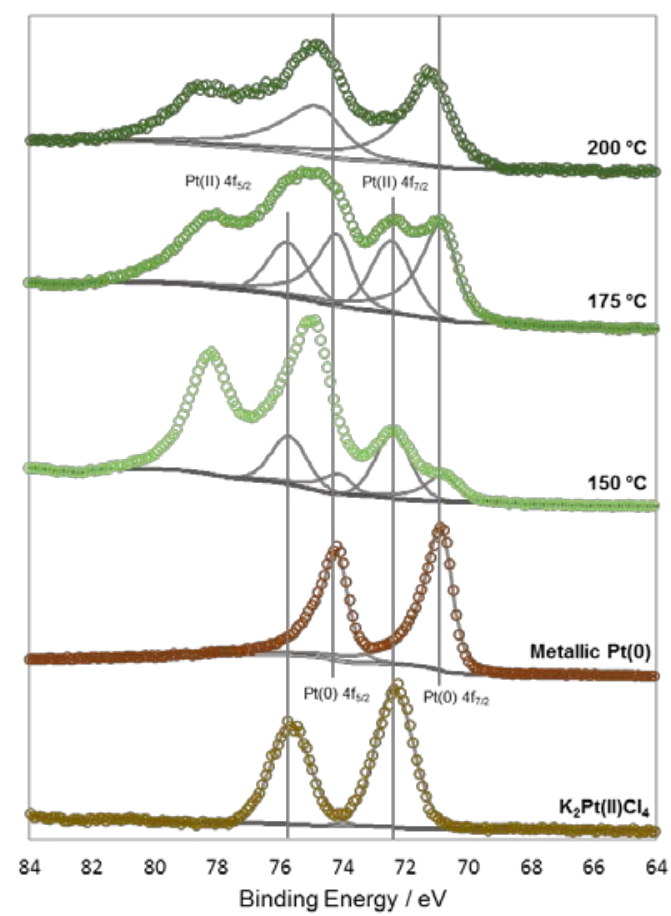

Figure SI3a. Stacked XPS data for the Pt/CUCIP materials activated at different temperatures, with the appropriate standards for comparisons showing the progressive decrease in Pt(II) content and the mirrored increase in $\mathrm{Pt}(\mathrm{O})$ species with increased activation temperature, with the final sample exhibiting complete formation of $\mathrm{Pt}(0)$. 


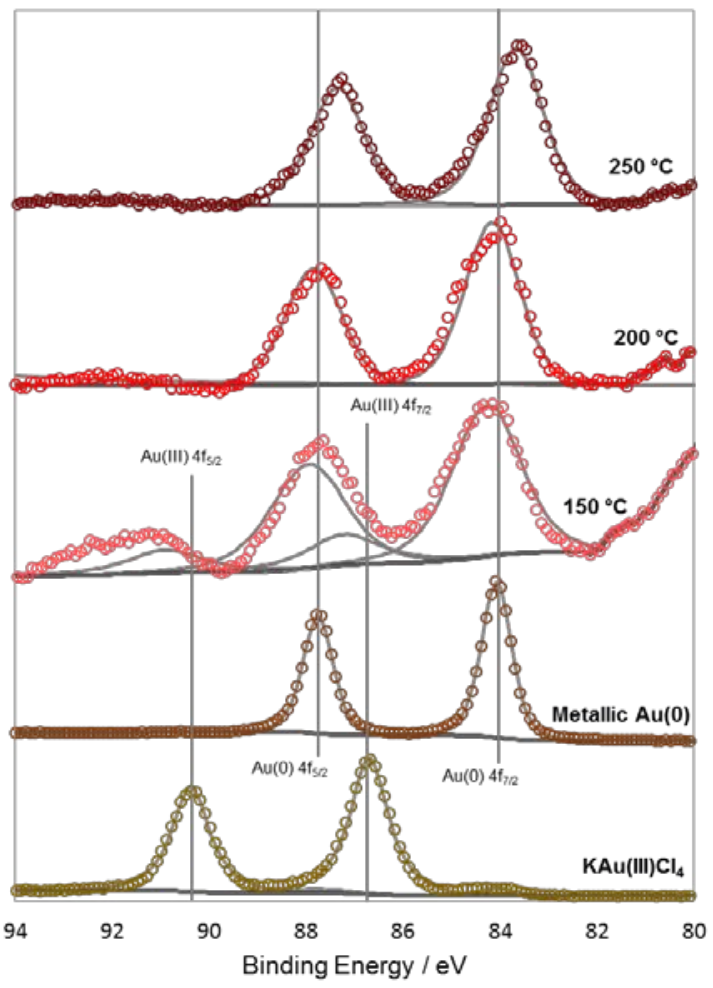

Figure SI3b. Stacked XPS data for the Au/CuCIP materials activated at different temperatures, with the appropriate standards for comparisons showing the loss of $A u(I I I)$ content and the complete formation of $\mathrm{Au}(0)$ at temperatures above $200^{\circ} \mathrm{C}$. 


\section{SI4. X-Ray Absorption Spectroscopy (XAS)}

$\mathrm{Pd}, \mathrm{Pt}$, and Au XAFS studies were carried out (analogously to previous investigations[22b]) on the B18 beamline at the Diamond Light Source, Didcot, UK. Measurements were performed using a QEXAFS set-up with a fast-scanning Si (111) or Si (311) double crystal monochromator. The normal time resolution of the spectra reported herein was $1 \mathrm{~min} / \mathrm{spectrum}\left(k_{\max }=16\right)$, on average six scans were acquired to improve the signal-to-noise level of the data. All samples were diluted with cellulose and pressed into pellets to optimize the effective edge-step of the XAFS data and measured in transmission mode using ion chamber detectors. All transmission XAFS spectra were acquired concurrently with the appropriate reference foil placed between $\mathrm{I}_{\mathrm{t}}$ and $\mathrm{I}_{\text {ref. }}$ XAS data processing and EXAFS analysis were performed using IFEFFIT with the Horae package (Athena and Artemis). ${ }^{[24]}$ The amplitude reduction factor, $\mathrm{So}^{2}$, was derived from EXAFS data analysis of known compounds, and used as a fixed input parameter.

\section{X-Ray Absorption Near Edge Structure (XANES)}

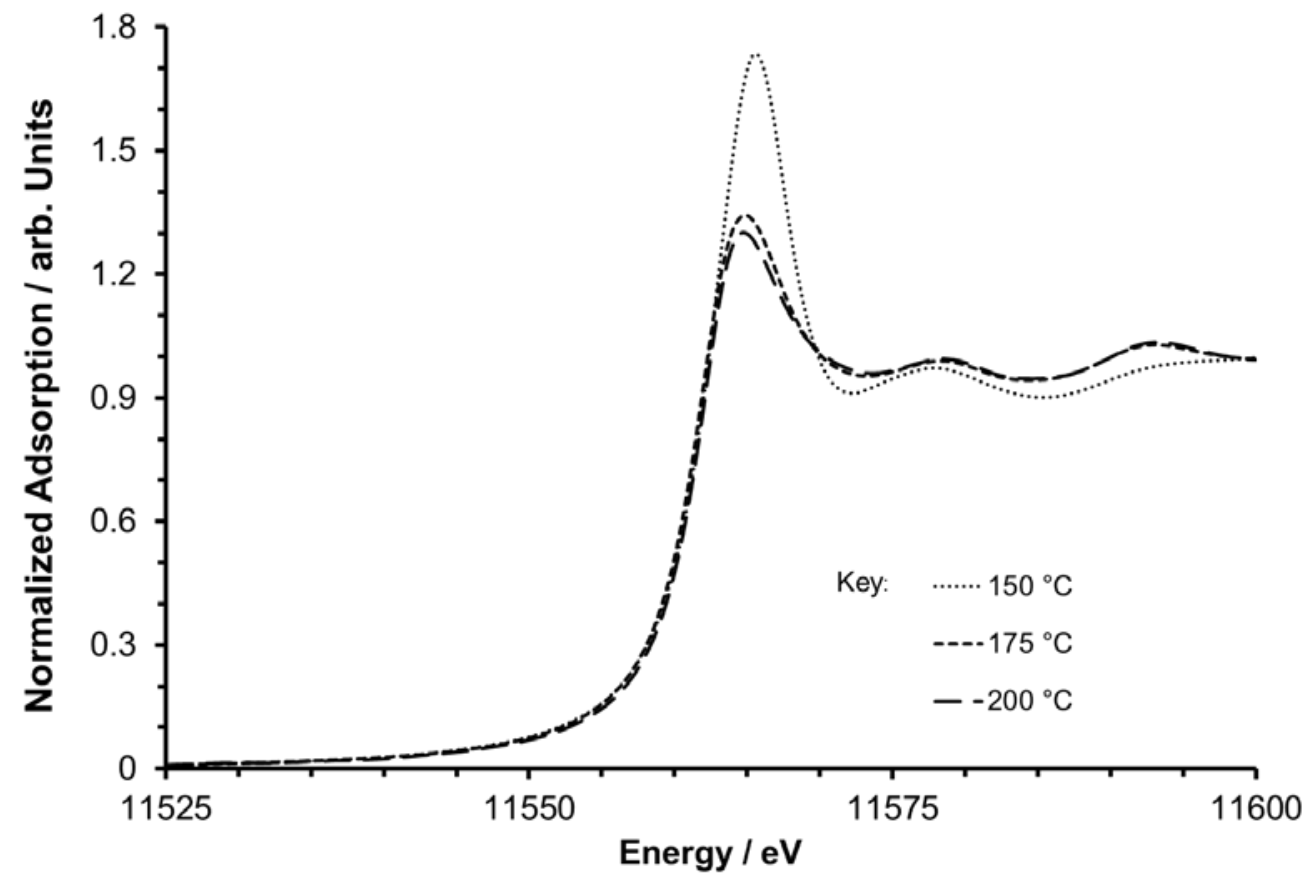

Figure SI4a. Stacked XANES data for the Pt/CUCIP materials activated at different temperatures, showing the progressive decrease in white line intensity as the activation temperature is increased, signifying the decrease in Pt oxidation state. 
Extended X-Ray Absorption Fine Structure (EXAFS)

Table SI4a. Pt EXAFS fitting parameters for the fits displayed in Figure $2 b$ in the main text.

\begin{tabular}{ccccccc}
\hline Sample & Abs Sc & $\mathbf{N}$ & $\mathbf{R} / \AA$ & $\mathbf{2 \sigma}^{2} / \AA^{2}$ & $\mathbf{E}_{\mathbf{f}} / \mathbf{e V}$ & $\mathbf{R}_{\text {factor }}$ \\
\hline \hline $\mathrm{Pt} / \mathrm{CuClP}$ & $\mathrm{Pt}-\mathrm{Cl}$ & $3.7(2)$ & $2.320(5)$ & $0.0027(3)$ & $9.5(8)$ & 0.012 \\
$150^{\circ} \mathrm{C}$ & $\mathrm{Pt}-\mathrm{Pt}$ & $3.4(5)$ & $2.768(7)$ & $0.0056(5)$ & & \\
& & & & & & \\
$\mathrm{Pt} / \mathrm{CuClP}$ & $\mathrm{Pt}-\mathrm{Cl}$ & $0.8(1)$ & $2.31(9)$ & $0.0026(8)$ & $7.9(7)$ & 0.006 \\
$175{ }^{\circ} \mathrm{C}$ & $\mathrm{Pt}-\mathrm{Pt}$ & $8.9(3)$ & $2.76(2)$ & $0.0059(1)$ & & \\
& & & & & \\
$\mathrm{Pt} / \mathrm{CuClP}$ & $\mathrm{Pt}-\mathrm{Cl}$ & $0.4(1)$ & $2.32(2)$ & $0.003(2)$ & $7.6(6)$ & 0.006 \\
$200^{\circ} \mathrm{C}$ & $\mathrm{Pt}-\mathrm{Pt}$ & $9.6(4)$ & $2.760(3)$ & $0.0059(2)$ & & \\
\hline
\end{tabular}

Pt sample $-S_{0}^{2}=0.91$ as deduced by Pt foil standard; Fit range $3<k<14,1.15<R<3$; \# of independent points $=12$.

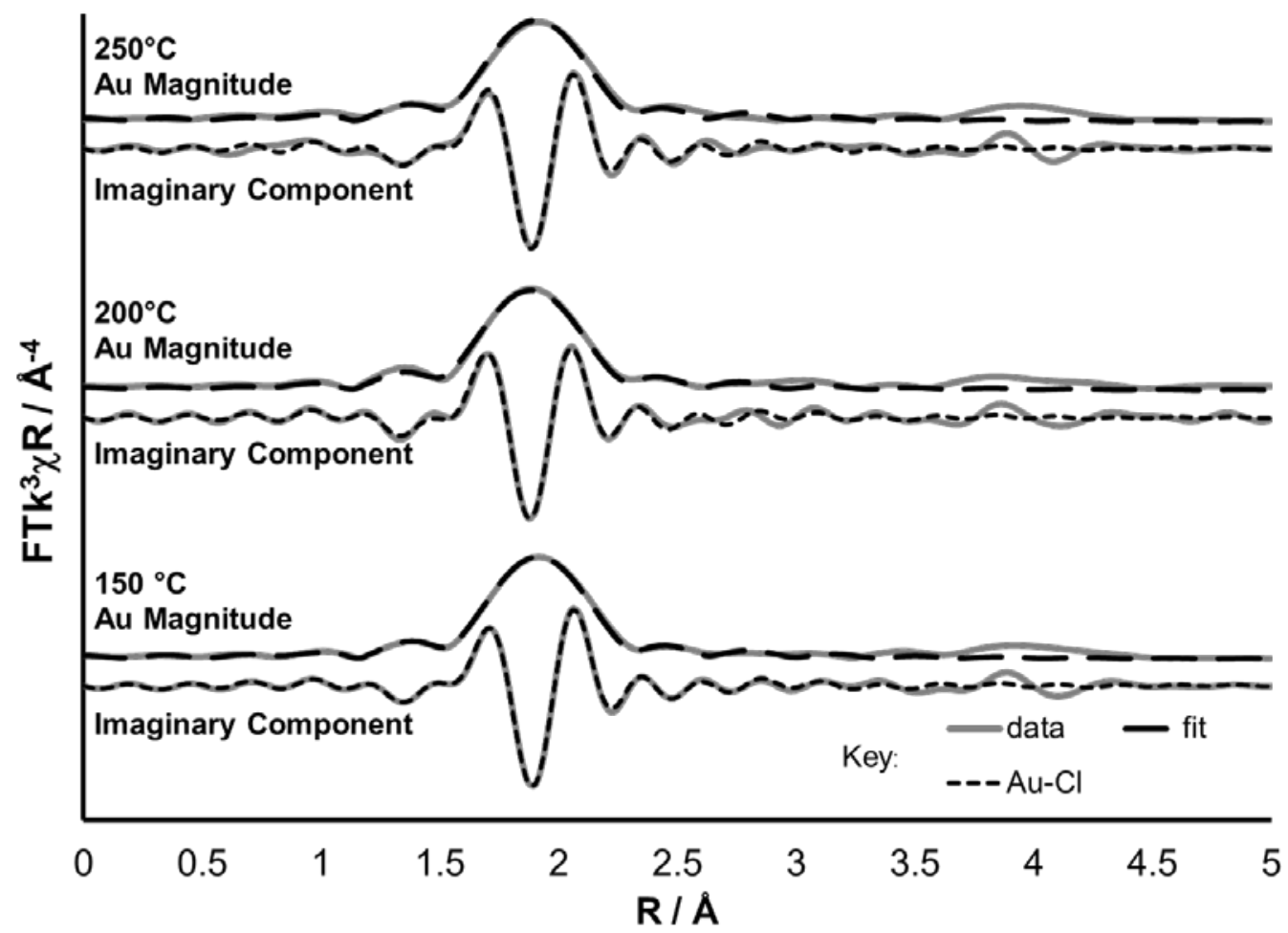

Figure SI4b. The magnitude and imaginary component of the $k^{3}$ weighted Fourier transform for the EXAFS data of the three Au/CUCIP species reduced under increasing activation temperatures, exhibiting the majority $\left[\mathrm{AuCl}_{4}\right]^{-}$precursor, with minimal signs for the reduction from the $\mathrm{Au}(\mathrm{III})$ towards $A u(0)$ in the bulk. Associated scattering paths are included for the imaginary component and the fitting parameters are displayed below. 
Table SI4b. Au EXAFS fitting parameters for the fits displayed in figure SI4b.

\begin{tabular}{ccccccc}
\hline Sample & Abs Sc & $\mathbf{N}$ & $\mathbf{R} / \AA$ & $\mathbf{2 \sigma ^ { 2 }} / \AA^{2}$ & $\mathbf{E}_{\mathbf{f}} / \mathbf{e V}$ & $\mathbf{R}_{\text {factor }}$ \\
\hline \hline $\begin{array}{c}\mathrm{Au} / \mathrm{CuClP} \\
150^{\circ} \mathrm{C}\end{array}$ & $\mathrm{Au}-\mathrm{Cl}$ & $3.7(1)$ & $2.287(4)$ & $0.0027(2)$ & $9.9(6)$ & 0.004 \\
$\begin{array}{c}\mathrm{Au} / \mathrm{CuClP} \\
200^{\circ} \mathrm{C}\end{array}$ & $\mathrm{Au}-\mathrm{Cl}$ & $2.24(7)$ & $2.269(4)$ & $0.0028(3)$ & $7.3(7)$ & 0.009 \\
$\begin{array}{c}\mathrm{Au} / \mathrm{CuClP} \\
250^{\circ} \mathrm{C}\end{array}$ & $\mathrm{Au}-\mathrm{Cl}$ & $3.1(1)$ & $2.282(5)$ & $0.0029(3)$ & $9.4(9)$ & 0.010 \\
\hline
\end{tabular}

$\mathrm{Au}$ sample $-\mathrm{S}_{0}^{2}=0.75$ as deduced by $\mathrm{KAuCl}_{4}$ standard; Fit range $3.5<k<12.5,1.1<R<3$; \# of independent points $=10$.

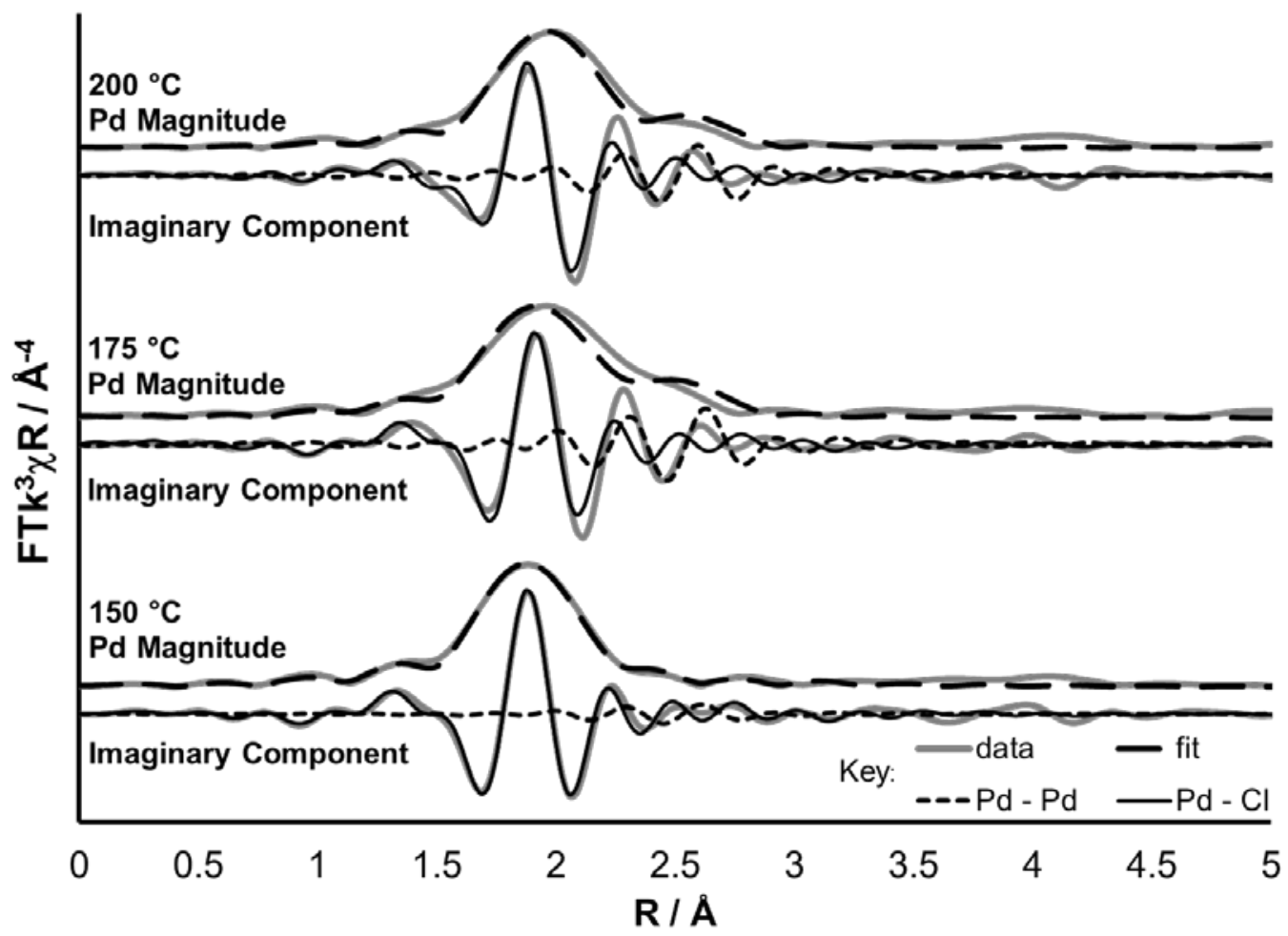

Figure SI4c. The magnitude and imaginary component of the $k^{3}$ weighted Fourier transform for the EXAFS data of the three Pd/CUCIP species reduced under increasing activation temperatures, demonstrating a minor reduction in $\mathrm{Pd}-\mathrm{Cl}$ contribution with increase in activation temperature. Associated scattering paths are included for the imaginary component and the fitting parameters are displayed below. 
Table SI4c. Pd EXAFS fitting parameters for the fits displayed in Figure SI4C.

\begin{tabular}{ccccccc}
\hline Sample & $\mathbf{A b s} \mathbf{S c}$ & $\mathbf{N}$ & $\mathbf{R} / \AA$ & $\mathbf{2 \sigma}^{2} / \AA^{\mathbf{2}}$ & $\mathbf{E}_{\mathbf{f}} / \mathbf{e V}$ & $\mathbf{R}_{\text {factor }}$ \\
\hline \hline $\mathrm{Pd} / \mathrm{CuClP}$ & $\mathrm{Pd}-\mathrm{Cl}$ & $4.2(1)$ & $2.322(5)$ & $0.0028(4)$ & $5.2(7)$ & 0.007 \\
$150{ }^{\circ} \mathrm{C}$ & $\mathrm{Pd}-\mathrm{Pd}$ & $0.3(2)$ & $2.76(3)$ & $0.003(3)$ & & \\
& & & & & & \\
$\mathrm{Pd} / \mathrm{CuClP}$ & $\mathrm{Pd}-\mathrm{Cl}$ & $3.2(3)$ & $2.35(1)$ & $0.003(1)$ & $4(2)$ & 0.041 \\
$175{ }^{\circ} \mathrm{C}$ & $\mathrm{Pd}-\mathrm{Pd}$ & $0.9(4)$ & $2.77(3)$ & $0.003(2)$ & & \\
& & & & & & \\
$\mathrm{Pd} / \mathrm{CuClP}$ & $\mathrm{Pd}-\mathrm{Cl}$ & $3.4(3)$ & $2.35(1)$ & $0.0027(7)$ & $13(1)$ & 0.025 \\
$200^{\circ} \mathrm{C}$ & $\mathrm{Pd}-\mathrm{Pd}$ & $0.9(4)$ & $2.77(2)$ & $0.002(2)$ & & \\
\hline
\end{tabular}

$P d$ sample $-S_{0}^{2}=0.82$ as deduced by $P d C l_{2}$ standard; Fit range $3<k<12,1<R<3$; \# of independent points $=11$. 


\section{SI5. Powder X-Ray Diffraction (PXRD)}

X-Ray diffraction patterns were collected on a Bruker D2 Phaser diffractometer.
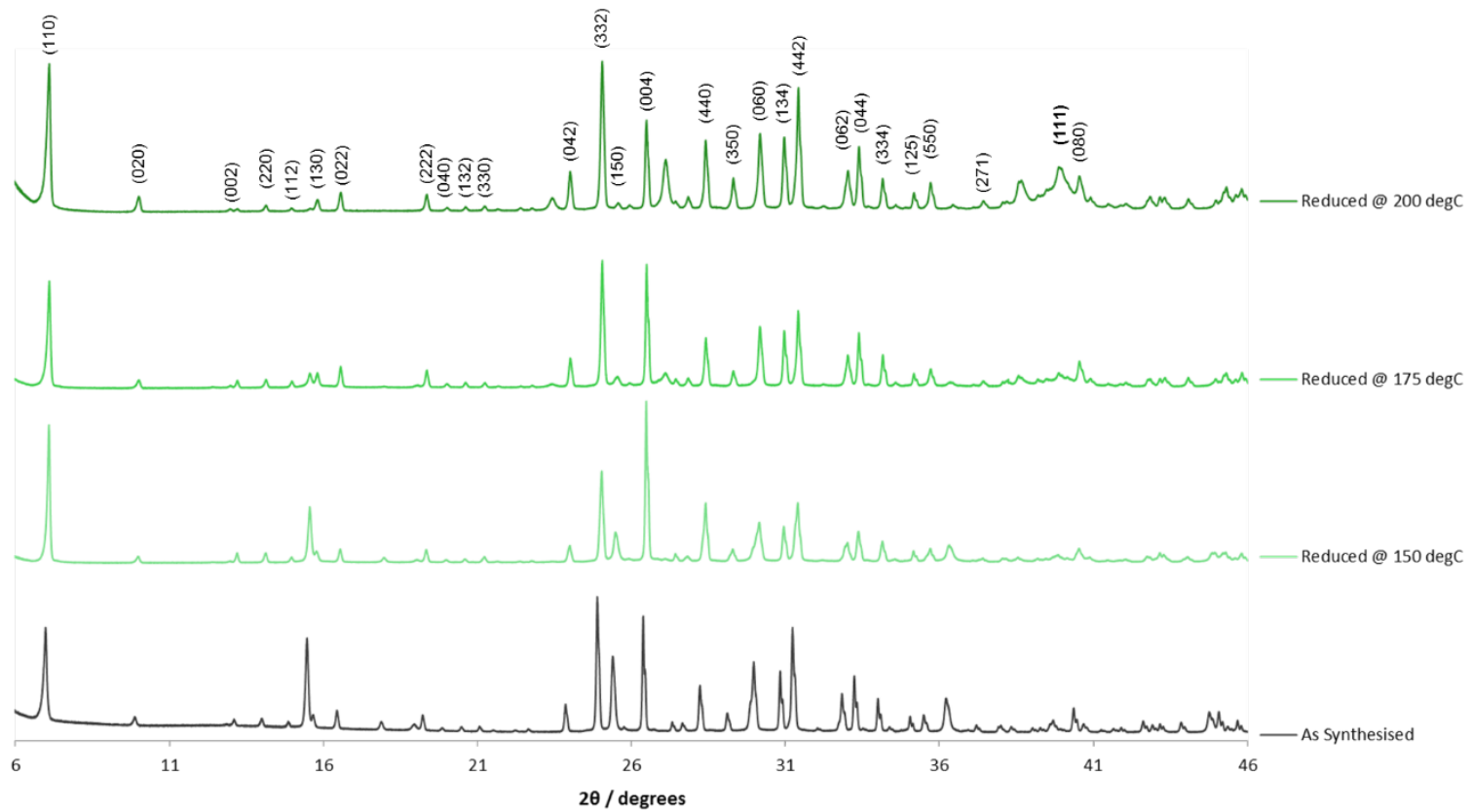

Figure SI5a. Indexed PXRD of the Pt/CUCIP materials activated at different temperatures (green) with the pre-activation, as-synthesized sample (grey) for comparison demonstrating both the structural integrity of the material at the various activation temperatures and a broad signal at $40^{\circ}$ assigned to the metallic Pt (111) (bold) reflection. Additionally the broad nature of the peak is indicative of small particle (nanoparticulate) size. ${ }^{[22 b]}$

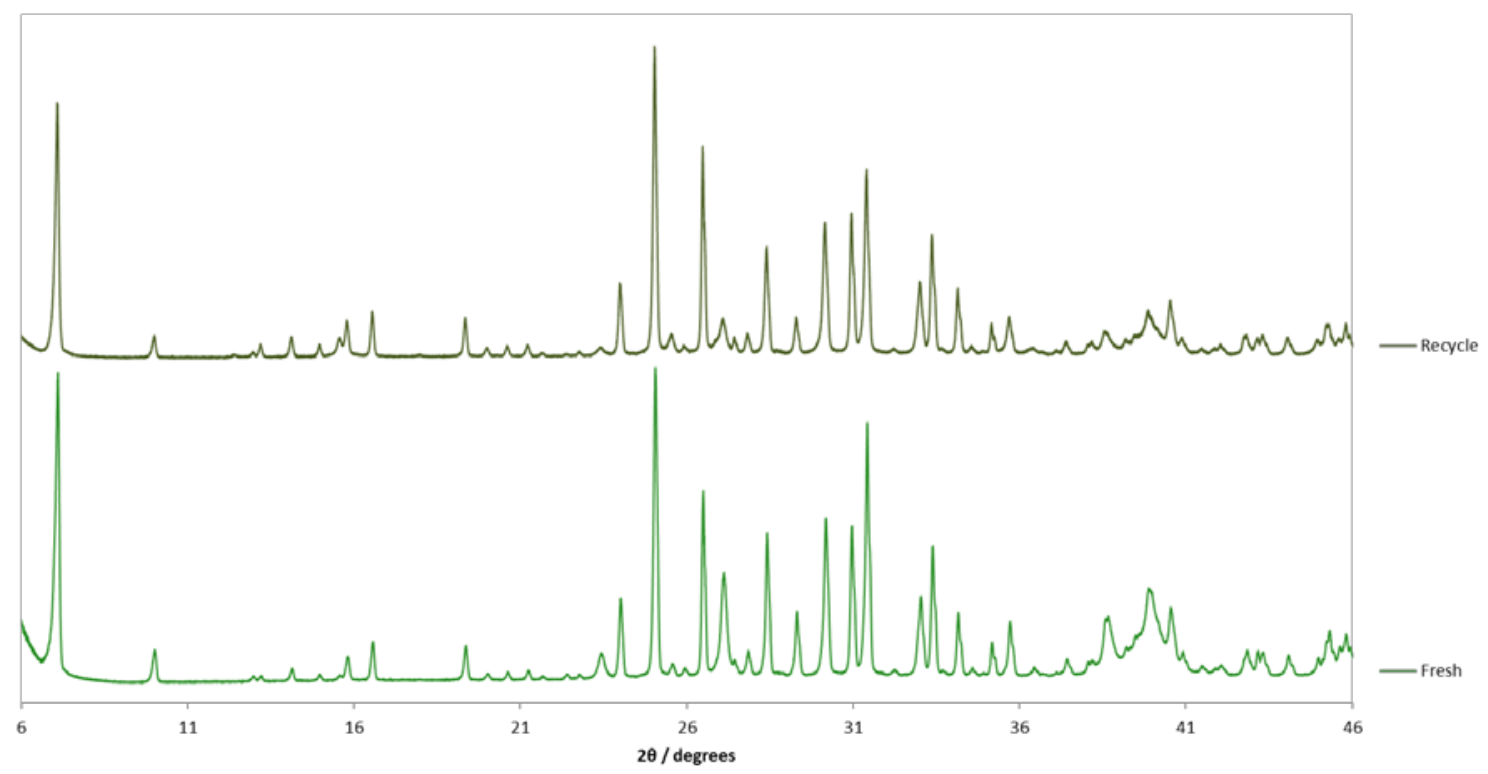

Figure SI5b. PXRD of the Pt/CuCIP materials activated at $200^{\circ} \mathrm{C}$ both before (fresh) and after catalysis (recycle) in the oxidation of KA-oil for $6 \mathrm{hr}$ signifying the robust nature and extended lifetime of these catalytic materials. 


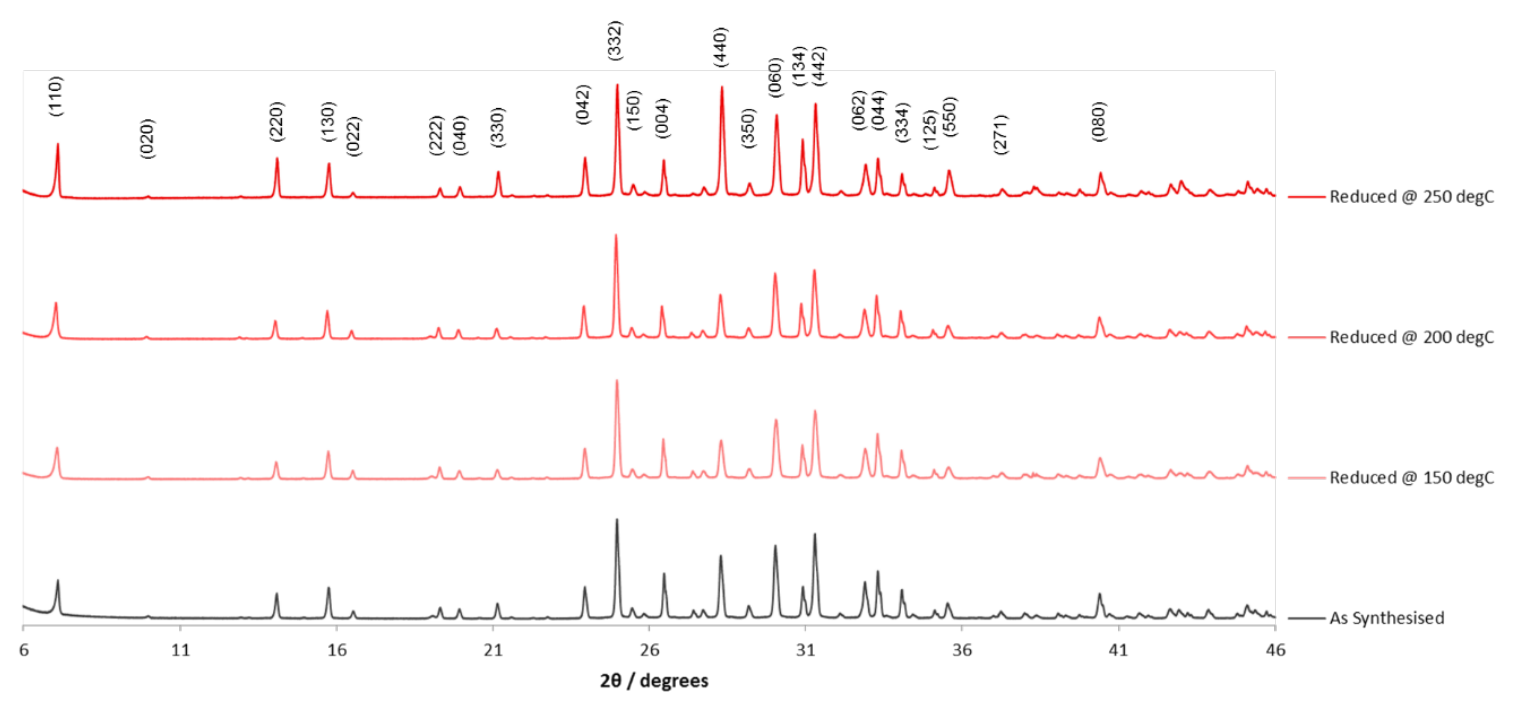

Figure SI5c. Indexed PXRD of the Au/CUCIP materials activated at different temperatures (red) with the pre-activation, as-synthesized sample (grey) for comparison demonstrating the structural integrity of the material at the various activation temperatures.

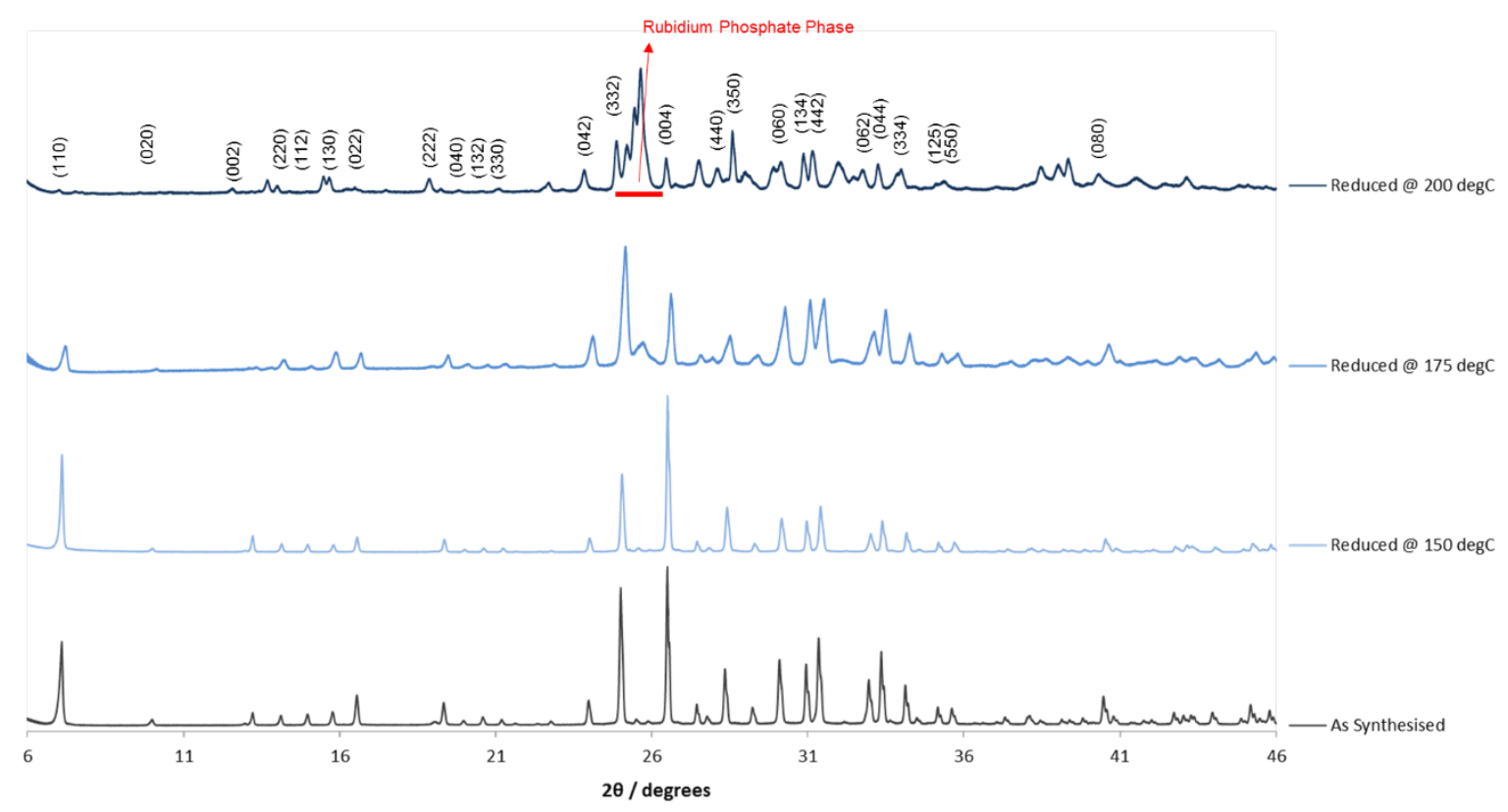

Figure SI5d. Indexed PXRD of the Pd/CUCIP materials activated at different temperatures (blue) with the pre-activation, as-synthesized sample (grey) for comparison, demonstrating the structural integrity of the material up to $175{ }^{\circ} \mathrm{C}$ and then the introduction of additional rubidium phosphate phases at temperatures close to $200{ }^{\circ} \mathrm{C}$. 


\section{SI6. Catalysis - Blanks}

Chemicals for catalytic tests were purchased from Sigma Aldrich or Fisher Scientific and used without further purification.

Catalytic reactions were carried out in a fixed-bed flow reactor using pelletized catalyst (approx. 0.24 g). The reactor assembly was set up and purged under the flow of air at $200{ }^{\circ} \mathrm{C}$ for one hour before the substrate feed was allowed to saturate the system. The substrate and airflow rates were adjusted to their experimental level and left to equilibrate for one hour. All reactions were carried out using an air flow of $25 \mathrm{mLmin}^{-1}$, a cyclohexanol flow of $7.5 \mu \mathrm{Lmin}^{-1}$ or a KA-oil flow of $15 \mu \mathrm{Lmin}^{-1}$ and at $200{ }^{\circ} \mathrm{C}$ unless stated otherwise. KA-oil solutions were made up of 50:50 \% wt. ratio of cyclohexanol and cyclohexanone.

An external standard solution of triethyleneglycol dimethyl ether $(1.96 \mathrm{M})$ in acetone was fed into the off stream of the reactor at the same rate as the substrate. The solution obtained was diluted at a ratio of $1: 10$ with acetone before being subject to $\mathrm{GC}$ analysis.

Samples were analyzed by GC (PerkinEImer, Clarus 480) using an Elite-5 column equipped with a flame ionization detector (FID). Products were identified against authenticated standards and quantified by calibration to obtain response factors $\left(R_{F}\right)$ against the known external standard.

Table SI6. Catalytic data from the aerobic oxidation of cyclohexanol and KA-oil, showing minimal levels of conversion for both the un-doped framework and the reactions in the absence of catalyst.

\begin{tabular}{cccccc}
\hline Catalyst & Substrate & $\begin{array}{c}\text { Temperature } \\
\boldsymbol{I}^{\circ} \mathbf{C}\end{array}$ & $\begin{array}{c}\text { Conversion } \\
\boldsymbol{I} \%\end{array}$ & $\begin{array}{c}\text { Cyclohexanone } \\
\text { Selectivity / \% }\end{array}$ & $\begin{array}{c}\text { Mass } \\
\text { Balance / \% }\end{array}$ \\
\hline \hline CuClP & Cyclohexanol & 200 & 1 & $>99$ & 95 \\
CuCIP & Cyclohexanol & 300 & 2 & $>99$ & 94 \\
& & & 1 & $>99$ & 97 \\
None & Cyclohexanol & 200 & 2 & $>99$ & 92 \\
None & Cyclohexanol & 300 & 3 & $>99$ & 94 \\
None & KA-oil & 200 & 3 & $>99$ & 93 \\
None & KA-oil & 300 & & & \\
\hline
\end{tabular}




\section{SI7. Full Catalytic Results}

\section{KA-Oil Oxidation}

Chemicals for catalytic tests were purchased from Sigma Aldrich or Fisher Scientific and used without further purification.

All reactions were carried analogously to SI6; using an air flow of $25 \mathrm{mLmin}^{-1}$, a substrate flow of 15 $\mu \mathrm{Lmin}^{-1}$ and at $200{ }^{\circ} \mathrm{C}$ unless stated otherwise. KA-oil solutions were made up of $50: 50 \%$ wt. ratio of cyclohexanol and cyclohexanone.

Table SI7a. Catalytic results summarizing the activities and selectivities of Au, Pt \& Pd catalysts activated under specific conditions (see SI1) in the aerobic oxidation of KA-oil. Data used for Figure $3 a$ in the main text, where mass-balances in excess of $95 \%$ have been used for evaluating comparative catalytic performances. Data collected after $1 \mathrm{~h}$ time-on-stream, see SI6 and SI7 for reaction conditions.

\begin{tabular}{|c|c|c|c|c|c|}
\hline Catalyst & $\begin{array}{c}\text { Activation } \\
\text { Temperature } I^{\circ} \mathrm{C}\end{array}$ & $\begin{array}{c}\text { WHSV I } \\
\mathrm{hr}^{-1}\end{array}$ & $\begin{array}{l}\text { Cyclohexanol } \\
\text { Conversion / \% }\end{array}$ & $\begin{array}{c}\text { Cyclohexanone } \\
\text { Selectivity / \% }\end{array}$ & $\begin{array}{c}\text { Mass Balance } \\
/ \%\end{array}$ \\
\hline$\overline{\mathrm{Au} / \mathrm{CuClP}}$ & 150 & (1.84 & "4 & $>999$ & $\bar{~} 95$ \\
\hline $\mathrm{Au} / \mathrm{CuCIP}$ & 175 & 1.65 & 4 & $>99$ & 91 \\
\hline $\mathrm{Au} / \mathrm{CuCIP}$ & 200 & 1.76 & 3 & $>99$ & 98 \\
\hline $\mathrm{Au} / \mathrm{CuCIP}$ & 250 & 1.71 & 1 & $>99$ & 94 \\
\hline $\mathrm{Pt} / \mathrm{CuCIP}$ & 150 & 1.81 & 7 & $>99$ & 90 \\
\hline $\mathrm{Pt} / \mathrm{CuCIP}$ & 175 & 1.74 & 16 & $>99$ & 92 \\
\hline $\mathrm{Pt} / \mathrm{CuCIP}$ & 200 & 1.76 & 74 & $>99$ & 97 \\
\hline $\mathrm{Pd} / \mathrm{CuCIP}$ & 150 & 1.84 & 1 & $>99$ & 99 \\
\hline $\mathrm{Pd} / \mathrm{CuCIP}$ & 175 & 1.82 & 1 & $>99$ & 97 \\
\hline $\mathrm{Pd} / \mathrm{CuCIP}$ & 200 & 1.77 & 5 & $>99$ & 93 \\
\hline
\end{tabular}

Table SI7b. Influence of time-on-stream on activity and selectivity in KA-oil oxidation using Pt/CuCIP (activated at $200^{\circ} \mathrm{C}$ ) catalyst. Data used for Figure $3 b$ in the main text. See SI6 and SI7 for reaction conditions

\begin{tabular}{cccc}
\hline Time I hr & $\begin{array}{c}\text { Cyclohexanol } \\
\text { Conversion I \% }\end{array}$ & $\begin{array}{c}\text { Cyclohexanone } \\
\text { Selectivity } \mathbf{\%}\end{array}$ & $\begin{array}{c}\text { Mass Balance } \\
\text { I \% }\end{array}$ \\
\hline \hline 1 & 72 & $>99$ & 99 \\
2 & 74 & $>99$ & 97 \\
3 & 76 & $>99$ & 87 \\
4 & 76 & $>99$ & 84 \\
5 & 74 & $>99$ & 87 \\
6 & 75 & $>99$ & 85 \\
7 & 74 & $>99$ & 86 \\
8 & 75 & $>99$ & 84 \\
9 & 74 & $>99$ & 86 \\
10 & 73 & $>99$ & 88 \\
\hline
\end{tabular}




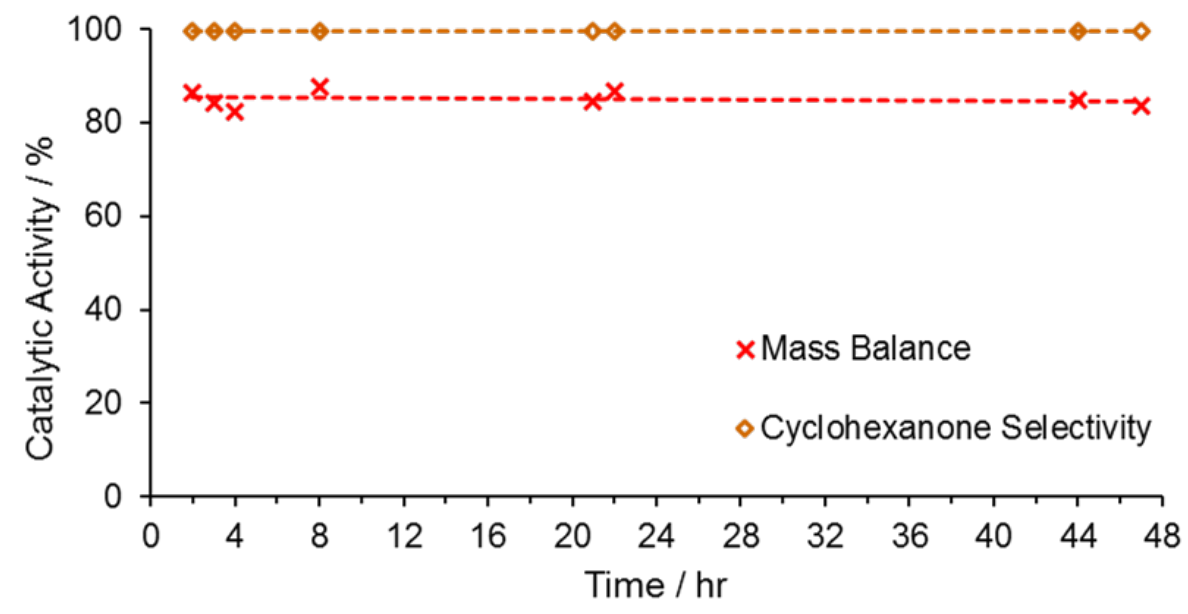

Figure SI7a. Time-on-stream data over a 48-hour period highlighting the consistent mass-balance and sustained cyclohexanone selectivity (>99\%) for the Pt/CuCIP (activated at $200{ }^{\circ} \mathrm{C}$ ) catalyst. Reaction temperature: $200^{\circ} \mathrm{C}$, air flow: $25 \mathrm{mLmin}^{-1}$, substrate flow: $15 \mu \mathrm{Lmin}^{-1}, \mathrm{WHSV}: 1.8 \mathrm{hr}^{-1}$. 


\section{Closed Loop Experiment}

The parameters described above were used. However, in order to mimic a closed loop system new substrate feed solutions were prepared to the measured molar ratio of the appropriate out stream.

i.e. After the initial purge the substrate $\left(15 \mu \mathrm{Lmin}^{-1}\right)$ and air $\left(25 \mathrm{mLmin}^{-1}\right)$ flow rates were set up and the system left to equilibrate for one hour. After which a sample was analyzed by GC (as above) and the cyclohexanol to cyclohexanone molar ratio determined. At which point a new substrate feed solution was made to the predetermined molar ratio of the previous sample. This process was repeated for the number of cycles shown in Table $6 \mathrm{~d}$.

Table SI7d. Catalytic data from closed-loop experiments involving the Pt/CuCIP catalyst (activated at $\left.200^{\circ} \mathrm{C}\right)$. See SI6 and SI7 for reaction conditions.

\begin{tabular}{ccccc}
\hline Cycle & $\begin{array}{c}\text { Substrate Feed Molar } \\
\text { Ratio (Cyol:Cyone) }\end{array}$ & $\begin{array}{c}\text { Cyclohexanol } \\
\text { Conversion / \% }\end{array}$ & $\begin{array}{c}\text { Cyclohexanone } \\
\text { Selectivity / \% }\end{array}$ & $\begin{array}{c}\text { Mass Balance } \\
\text { / \% }\end{array}$ \\
\hline \hline 1 & $1: 1$ & 67 & $>99$ & 88 \\
2 & $0.5: 1$ & 81 & $>99$ & 85 \\
3 & $0.1: 1$ & 93 & $>99$ & 84 \\
4 & $0.04: 1$ & 95 & $>99$ & 90 \\
\hline
\end{tabular}




\section{SI8. Transmission Electron Microscopy (TEM)}

Aberration-corrected TEM was performed on an FEI Titan ${ }^{3}$ 80-300 (S)TEM equipped with a CEOS CESCOR aberration corrector in the probe forming lens. The Titan was operated at 80 or $300 \mathrm{kV}$, employing annular dark-field (ADF) aberration-corrected scanning TEM (AC-STEM) as the primary investigative technique. Samples were prepared for the STEM analysis by dusting the dry powder onto standard copper TEM support grids with holey carbon support film. Between analyses, samples were stored in a vacuum desiccator with anhydrous calcium sulfate desiccant. Under various combinations of electron beam current, dwell time and pixel size (magnification), and at both 80 and $300 \mathrm{kV}$, all samples were found to be highly susceptible to beam-induced damage. Considerable care was therefore taken to obtain representative images before overwhelming beam-induced modification of the samples occurred.

ADF AC-STEM images corresponding to those in the main manuscript but showing larger areas, as well as additional illustrative images, are shown in Figures SI8a-c.
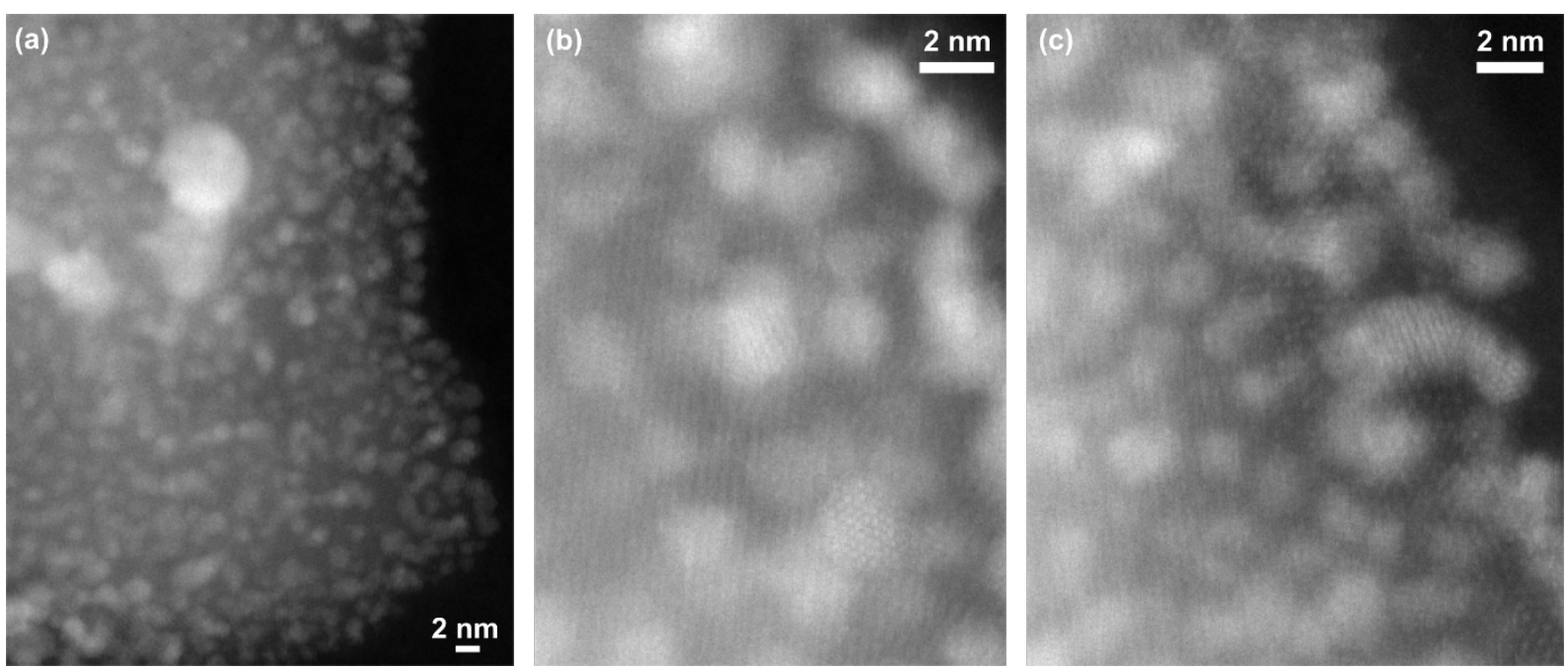

Figure SI8a. ADF AC-STEM images of the Pt/CUCIP material activated at $200{ }^{\circ} \mathrm{C}$. (a) Nanoparticle formation across the framework (nanoparticle size in this area $\sim 2-3 \mathrm{~nm}$ in diameter). (b,c) Highresolution images of the nanoparticles, in which the measured $d$-spacing's are consistent with nanocrystalline Pt. The crystalline integrity of the framework is also rendered visible, by virtue of the framework lattice planes containing heavy-metal atoms. 

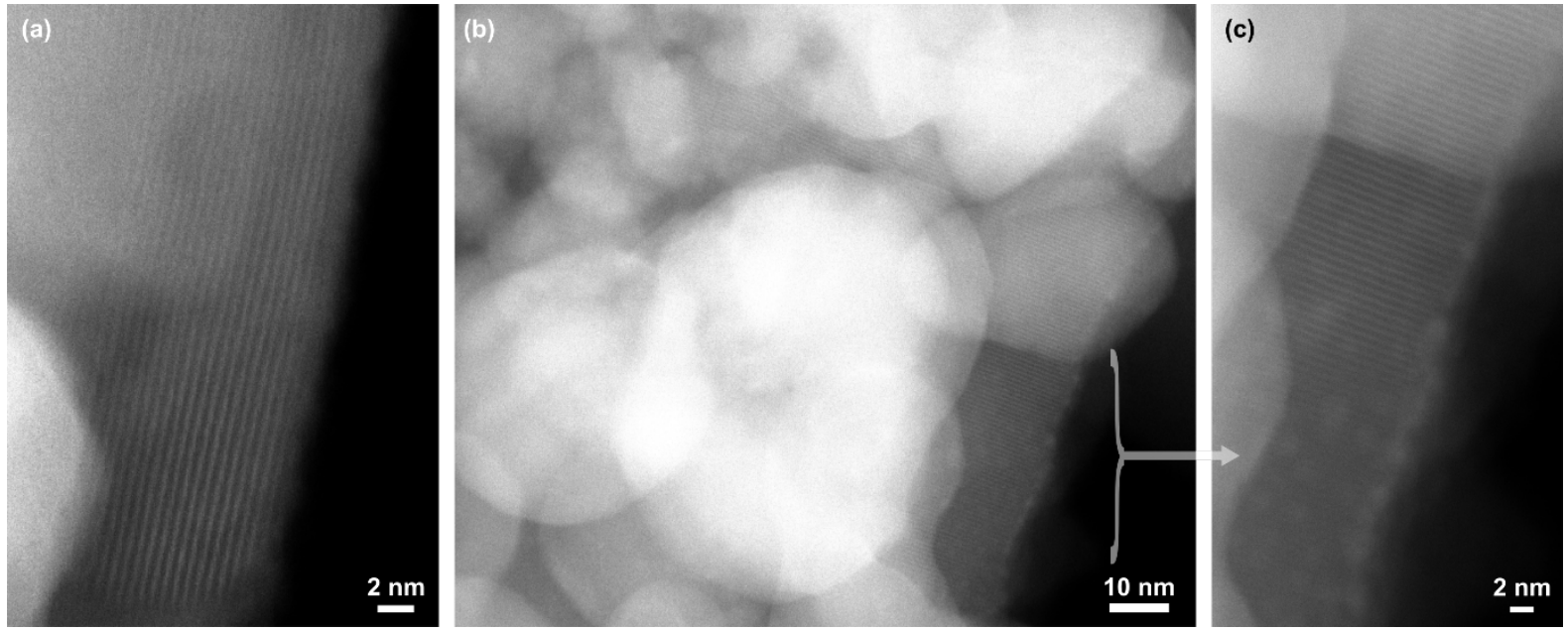

Figure SI8b. ADF AC-STEM images of the Pd/CUCIP material activated at $200^{\circ} \mathrm{C}$. (a) Crystalline structure of the framework rendered visible by the framework lattice planes containing heavy metal atoms. Here no nanoparticle formation is observed. $(b, c)$ Limited nanoparticle formation, with a suggestion of higher propensity to form on the surface of the support, as highlighted in (c).
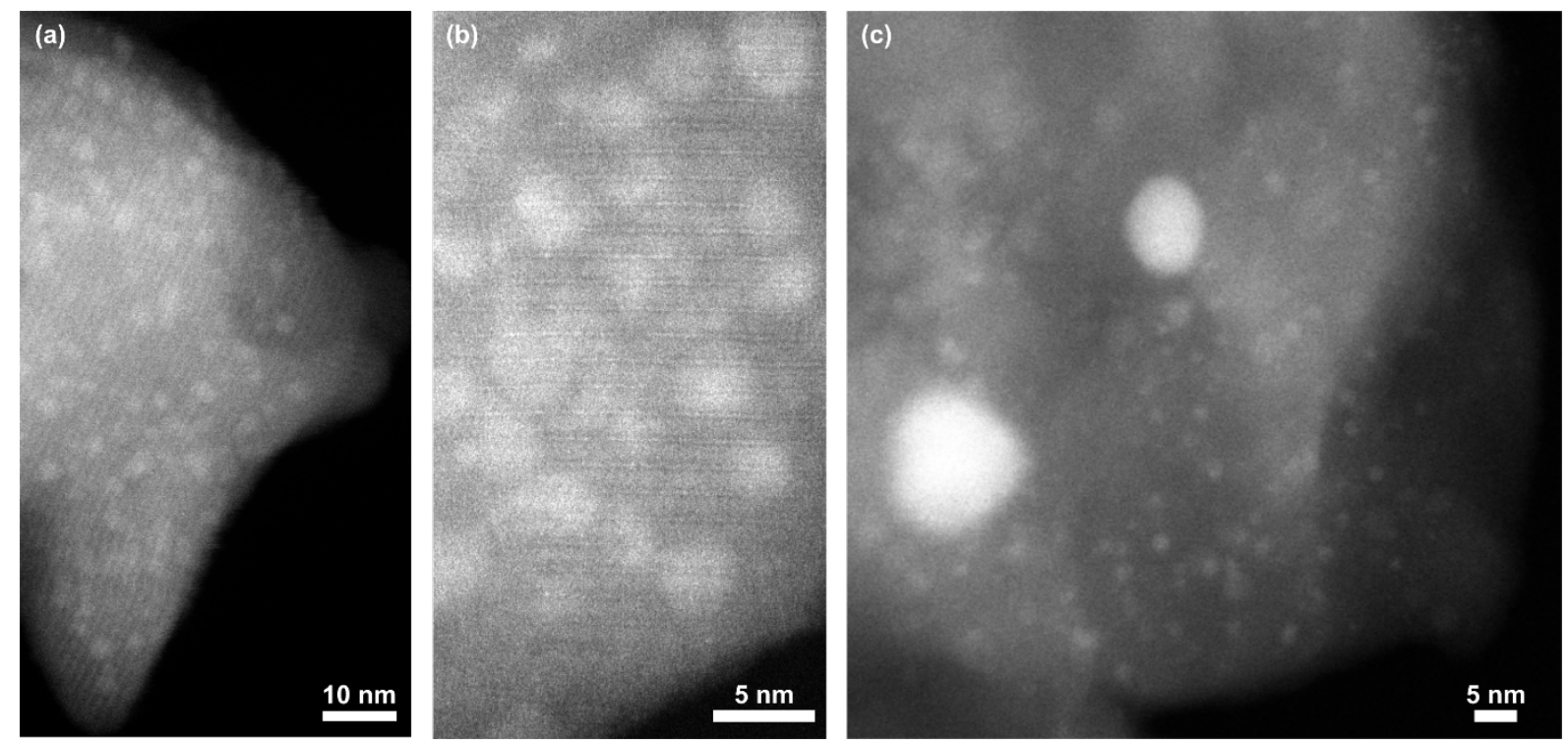

Figure SI8c. ADF AC-STEM images of the Au/CUCIP material activated at $200{ }^{\circ} \mathrm{C}$. Nanoparticle formation is abundant across the framework, whose crystalline structure is rendered visible in both (a) and (b) via heavy metal atom containing lattice planes of the framework. (c) In addition to the small nanoparticles, significant larger nanoparticles are also present. 


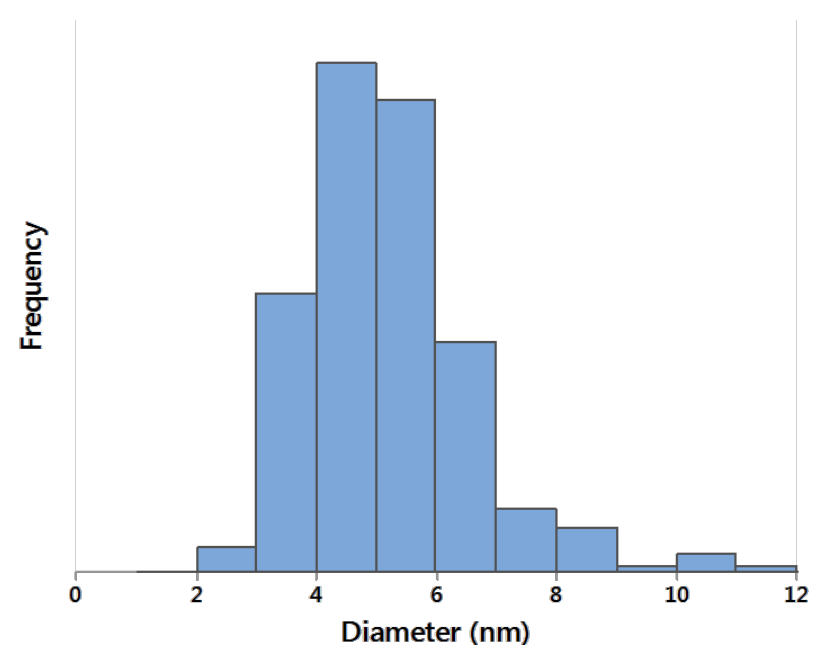

Figure SI8d. NP size distribution histogram (displaying a mean particle diameter of $5.2 \mathrm{~nm}$ (standard deviation, $1.4 \mathrm{~nm})$ ) for the Pt/CuCIP post-catalysis across a 266 particle sample range, which clearly reveals very little restructuring or agglomeration of the NPs, when compared with their as-synthesized analogues..$^{22}$ The mean particle-size difference is $0.2 \mathrm{~nm}$, which further indicates that there is very little effect on the nanoparticle speciation throughout the reaction. 


\section{SI9. Energy-Dispersive X-Ray Spectroscopy (EDXS)}

EDXS was performed on an FEI Tecnai Orisis 80-200 (S)TEM operated at $80 \mathrm{kV}$, equipped with an FEI Super-X EDXS system. Spectral processing was performed using the FEI TIA and HyperSpy (http://hyperspy.org) software packages.

To verify overall composition, for all samples, EDX spectra were acquired and integrated from large regions across the micron-sized as well as smaller fragments of the samples. Characteristic regions of the samples typically showed presence of the expected constituent elements (viz. Pt, $\mathrm{Pd}$ or $\mathrm{Au}$ and $\mathrm{Cu}$, $\mathrm{Rb}, \mathrm{Cl}, \mathrm{O}, \mathrm{P}$ ), as seen in the example spectra of Figures SI9a-c. Some (usually small in size and prevalence) fragments showed presence of $\mathrm{F}, \mathrm{Ca}, \mathrm{F}$ or $\mathrm{Si}$ impurities and/or absence of expected constituent elements, which may be remnants from the synthesis process, contamination during synthesis, sample storage or TEM sample preparation, or the result of segregation over time.

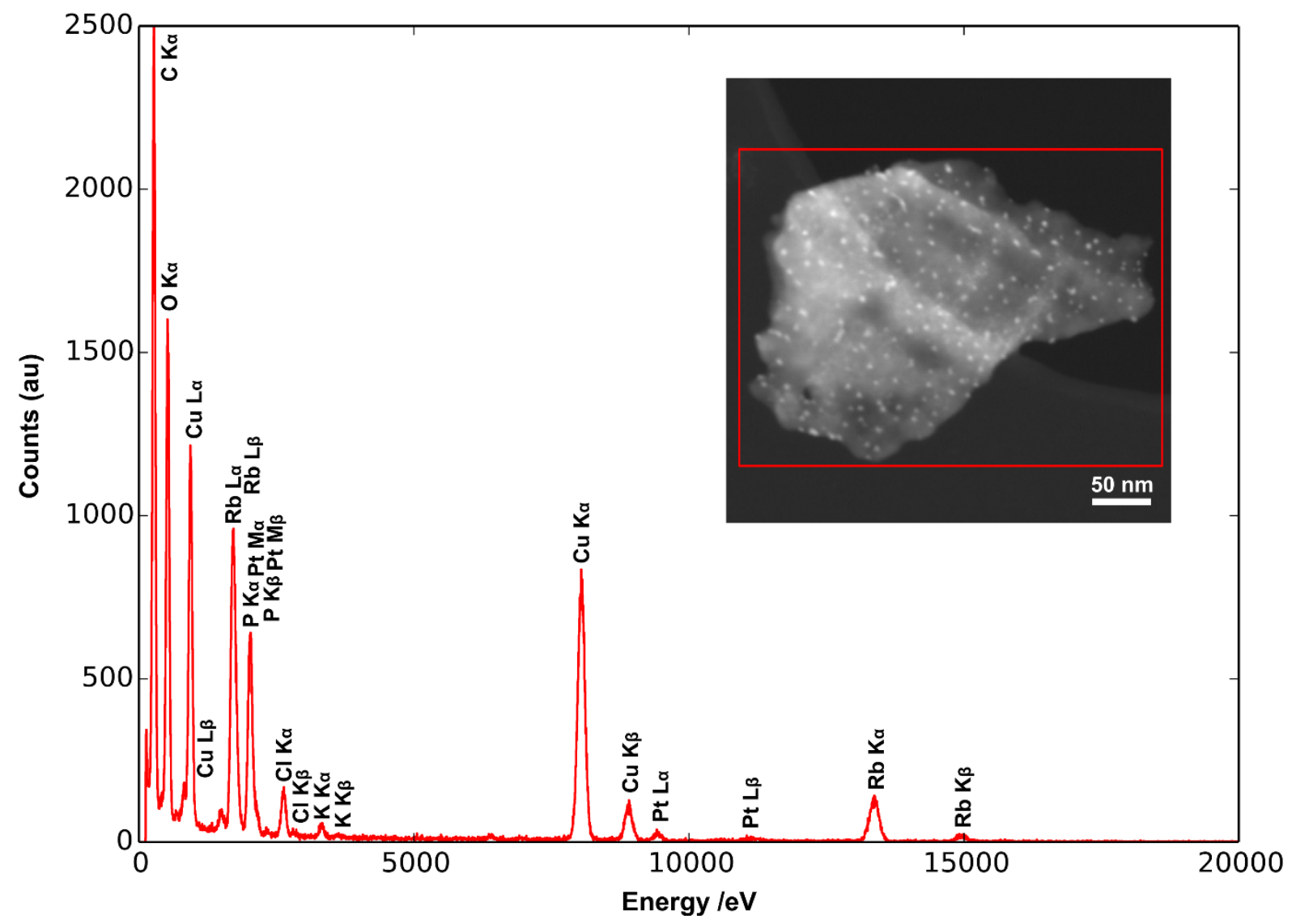

Figure SI9a. EDX spectrum for the Pt/CuCIP material activated at $200{ }^{\circ} \mathrm{C}$. The area analyzed is indicated by the red box in the inset ADF-STEM image. 


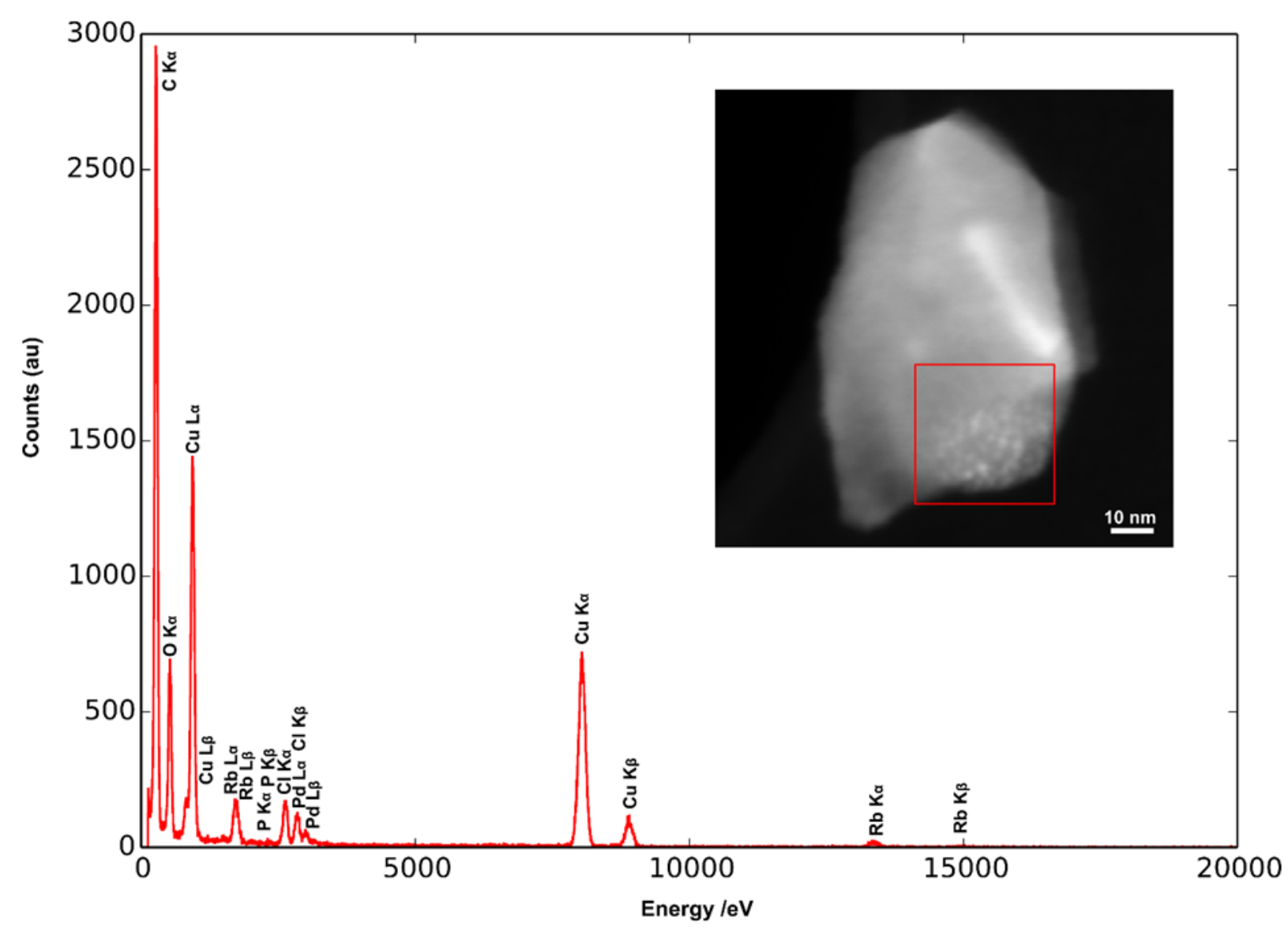

Figure SI9b. EDX spectrum for the Pd/CuCIP material activated at $200{ }^{\circ} \mathrm{C}$. The area analyzed is indicated by the red box in the inset ADF-STEM image. 


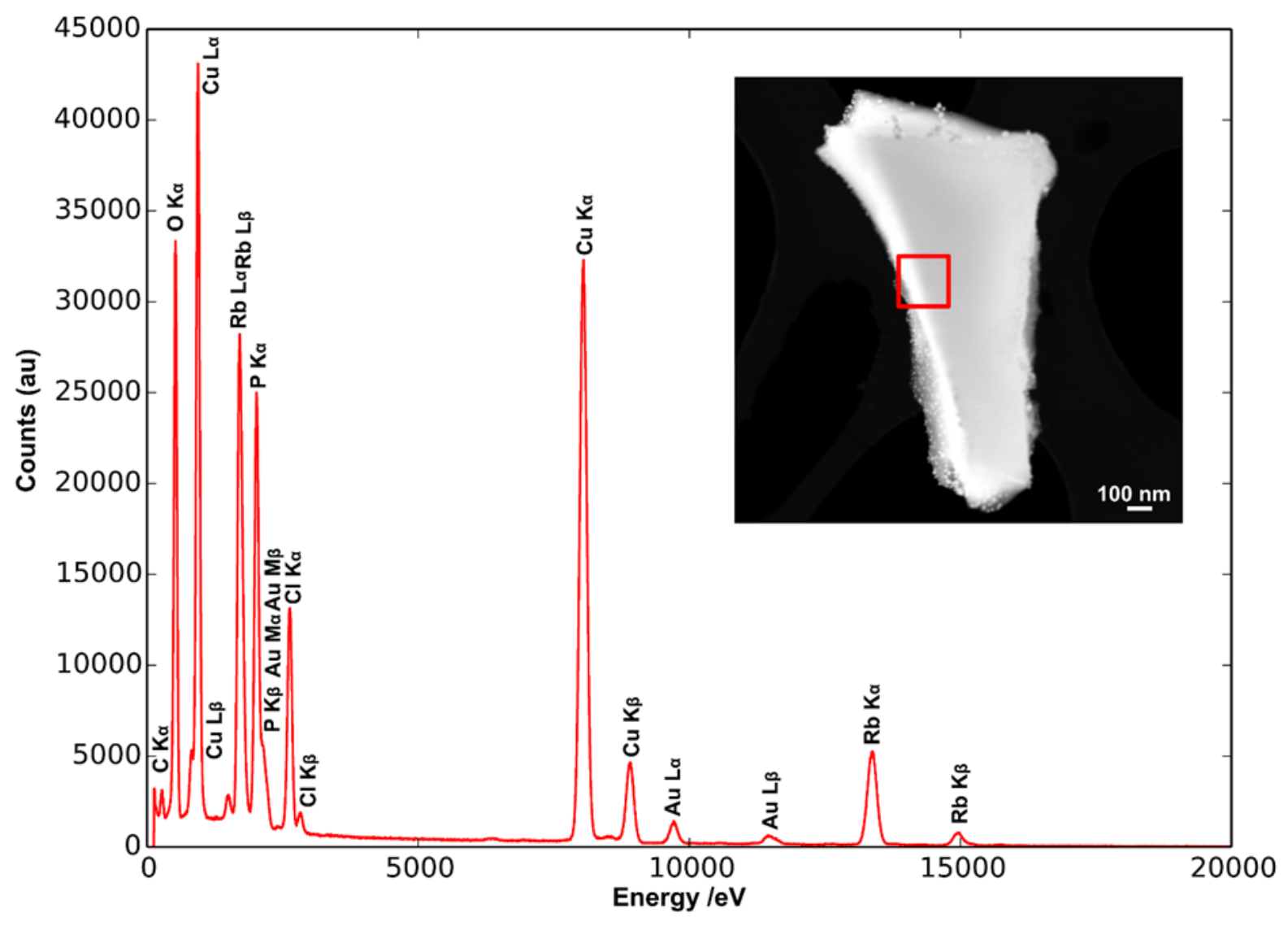

Figure SI9c. EDX spectrum for the Au/CuCIP material activated at $200{ }^{\circ} \mathrm{C}$. The area analyzed is indicated by the red box in the inset ADF-STEM image. 


\section{Bibliography}

[1] B. Z. Zhan, M. A. White, T. K. Sham, J. A. Pincock, R. J. Doucet, K. V. R. Rao, K. N. Robertson, T. S. Cameron, J. Am. Chem. Soc. 2003, 125, 2195-2199.

[2] J. C. Beziat, M. Besson, P. Gallezot, Appl. Catal. A: General. 1996, 135, L7-L11.

[3] Y. Hong, X. Yan, X. Liao, R. Li, S. Xu, L. Xiao, J. Fan, Chem. Commun. 2014, 50, 96799682.

[4] S. A. Chavan, D. Srinivas, P. Ratnasamy, J. Catal. 2002, 212, 39-45.

[5] N. Jappar, Q. Xia, T. Tatsumi, J. Catal. 1998, 180, 132-141.

[6] A. Corma, P. Esteve, A. Martinez, J. Catal. 1996, 161, 11-19.

[7] J. Ni, W. J. Yu, L. He, H. Sun, Y. Cao, H. Y. He, K. N. Fan, Green Chem. 2009, 11, 756-759.

[8] R. Raja, J. M. Thomas, M. Greenhill-Hooper, V. Doukova, Chem. Commun. 2007, 19, 19241926.

[9] K. Yamaguchi, N. Mizuno, New J. Chem. 2002, 26, 972-974.

[10] T. Wang, H. Shou, Y. Kou, H. Liu, Green Chem. 2009, 11, 562-568.

[11] C. G. Jia, F. Y. Jing, W. D. Hu, M. Y. Huang, Y. Y. Jiang, J. Mol. Catal. 1994, 91, 139-147.

[12] H. Ji, T. Mizugaki, K. Ebitani, K. Kaneda, Tetrahedron Lett. 2002, 43, 7179-7183.

[13] H. Wang, W. Kong, W. Zhu, L. Wang, S. Yang, F. Liu, Catal. Commun. 2014, 50, 87-91.

[14] V. Mahdavi, S. Soleimani, Mater. Res. Bull. 2014, 51, 153-160.

[15] Z. Yang, J. Li, X. Yang, X. Xie, Y. Wu, J. Mol. Catal. A: Chem. 2005, 241, 15-22.

[16] A. Romero, A. Santos, D. Escrig, E. Simon, Appl. Catal. A: General. 2011, 392, 19-27.

[17] G. K. Reddy, P. K. Rao, Catal. Lett. 1997, 45, 93-96.

[18] R. Rao, S. K. Meher, B. G. Mishra, P. H. K. Charan, Catal. Today. 2012, 198, 140-147.

[19] M Popova, A. Szegedi, K. Lazar, A. Dimitrova, Catal. Lett. 2011, 141, 1288-1296.

[20] B. M. Nagaraja, A. H. Padmasri, P. Seetharamulu, K. H. P. Reddy, B. D. Raju, K. S. R. Rao, J. Mol. Catal. A: Chem. 2007, 278, 29-37.

[21] D. Santhanaraj, C. Suresh, P. Vijayan, N. Venkatathri, Reac. Kinet. Mech. Cat. 2010, 99, 439-446.

[22] a) C. S. Hinde, S. Van Aswegen, G. Collins, J. D. Holmes, T. S. A. Hor, R. Raja, Dalt. Trans. 2013, 42, 12600-12605; b) C. S. Hinde, D. Ansovini, P. P. Wells, G. Collins, S. Van Aswegen, J. D. Holmes, T. S. A. Hor, R. Raja, ACS Catal. 2015, 5, 3807-3816.

[23] E. R. Williams, R. M. Leithall, R. Raja, M. T. Weller, Chem. Commun. 2013, 49, 249-251.

[24] a) M. Newville, J. Synchrotron. Radtiat. 2001, 8, 322-324; b) B. Ravel, M. Newville, J. Synchrotron. Radiat. 2005, 12, 537-541. 